\title{
Enantiospecific behaviour of chiral drugs in soil.
}

\author{
BERTIN, S.,YATES, K. and PETRIE, B.
}




\section{Enantiospecific behaviour of chiral drugs in soil}

2 Sophie Bertin ${ }^{\mathrm{a}}$, Kyari Yates ${ }^{\mathrm{a}}$, Bruce Petrie ${ }^{\mathrm{a}^{*}}$

5

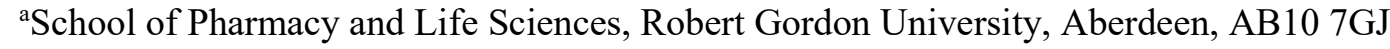

*Corresponding author email: b.r.petrie@rgu.ac.uk Tel. +44 (0)1224 262824

\section{Abstract}

The importance of stereochemistry on the behaviour and effects of chiral pharmaceutical and illicit drugs in amended agricultural soils has been over looked to date. Therefore, this study was aimed at investigating the enantiospecific behaviour of a chemically diverse range of chiral drugs including naproxen, ibuprofen, salbutamol, bisoprolol, metoprolol, propranolol, acebutolol, atenolol, chlorpheniramine, amphetamine, fluoxetine and citalopram in soil microcosms. Considerable changes of the enantiomeric composition of ibuprofen, naproxen, atenolol, acebutolol and amphetamine were observed within $56 \mathrm{~d}$. This is significant as enantiomer enrichment can favour the pharmacologically active (e.g., $S(-)$-atenolol) or less/non-active forms of the drug (e.g., $R(-)$-amphetamine). Single enantiomer microcosms showed enantiospecific degradation was responsible for enantiomer enrichment of atenolol and amphetamine. However, naproxen and ibuprofen enantiomers were subject to chiral inversion whereby one enantiomer converts to its antipode. Interestingly, chiral inversion was bidirectional and this is the first time it is reported in soil. Therefore, introduction of the less active enantiomer to soil through irrigation with reclaimed wastewater or biosolids as fertiliser can result in the formation of its active enantiomer, or vice versa. This phenomenon needs considered in risk assessment frameworks to avoid underestimating the risk posed by chiral drugs in amended soils.

\section{Capsule}

Changes to the enantiomeric composition of chiral drugs in soil due to enantiospecific degradation (e.g., atenolol and amphetamine) or chiral inversion (e.g., ibuprofen and naproxen) could result in the underestimation of environmental risk.

Keywords: pharmaceutical; soil; microcosm; enantiomer; inversion 


\section{Introduction}

27 Human pharmaceutical and illicit drugs are emerging contaminants as their fate and effects in the environment are not fully understood (Petrie et al., 2015; Noguera-Oviedo and Aga, 2016). It is well established that drugs are incompletely removed during wastewater treatment and are found in both treated wastewater and sludge (or biosolids) (McClellan and Halden, 2010; Gardner et al., 2012). Most research has focussed on the fate and impact of drugs in the aquatic environment (Hughes et al., 2013; Petrie et al., 2015). However, irrigation of farmland with treated wastewater and application of biosolids as fertiliser are growing practices that introduce drugs to the terrestrial environment. Pharmaceutical drugs have been shown to exert toxicity to exposed organisms such as Eisenia fetida, which are essential for soil function (Pino et al., 2015). Additionally, bioaccumulation is possible, posing a risk to organisms in higher trophic levels (Kinney et al., 2008). Drugs are also taken up by plants from soils, including those grown for human consumption (Malchi et al., 2014; Wu et al., 2014).

Understanding the behaviour of drugs in amended soils is essential for the development of accurate environmental risk assessment (ERA). Degradation studies have found half-lives $\left(t_{1 / 2}\right)$ can range from a few days (e.g., diclofenac) to >200 days (e.g., carbamazepine) (Monteiro and Boxall, 2009; Xu et al., 2009; Lin and Gan, 2011; Grossberger et al., 2014), demonstrating the diverse behaviour of drugs in the environment. An important consideration for assessing both the degradation and toxicity of drugs in the environment is their stereochemistry (Kasprzyk-Hordern, 2010). More than $50 \%$ of pharmaceutical drugs on the market are chiral and exist as two or more enantiomers (Sanganyado et al., 2017). Chiral drugs are usually marketed as racemic mixtures (equimolar concentration of enantiomers), or as single enantiomer preparations. However, chiral drugs are often subject to enantiospecific degradation and toxicity in the environment (Stanley et al., 2006; Stanley et al., 2007; Bagnall et al., 2013; Evans et al., 2017; Petrie et al., 2018). Failing to consider the enantioselectivity of drugs in soils can result in the overestimation or underestimation of risk posed. Current ERA approaches do not require analysis at the enantiomeric level. Consequently, there is a paucity of data on the enantiospecific 
Several studies have investigated the degradation of chiral drugs in soil (Monteiro and Boxall, 2009; Xu et al., 2009; Carr et al., 2011; Lin and Gan, 2011; Grossberger et al., 2014). However, most do not consider the role of stereochemistry on drug degradation. Furthermore, they do not report the enantiomeric composition of chiral drugs used in spiking studies (Xu et al., 2009; Lin and Gan, 2011; Grossberger et al., 2014). This is significant considering some analytical standards are available as racemates or in enantiomerically pure forms such as the anti-inflammatory drugs ibuprofen and naproxen. Considering enantiomers of the same drug can behave differently in soil, conclusions drawn from such studies could be misrepresentative. Preliminary studies undertaken at the enantiomeric level found considerable changes to the enantiomeric distribution of the stimulant amphetamine and the betablocker atenolol in soil microcosms (Petrie et al., 2018). For example, an initial amphetamine enantiomeric fraction (EF) of 0.5 (racemic) changed to 0.1 after $3 \mathrm{~d}$ incubation. The enrichment of $R(-$ )-amphetamine was postulated as being the result of the comparatively faster degradation of $S(+)$ amphetamine (Petrie et al., 2018). Nevertheless, there is limited information on drugs that transform enantioselectively, or the processes responsible for these transformations. Both enantioselective degradation and/or chiral inversion can take place under environmental conditions (Sanganyado et al., 2017). Chiral inversion is the conversion of one enantiomer into its antipode without any other structural changes (Hutt and Caldwell, 1983). This process is significant as a non-toxic enantiomer in the environment has potential to convert into the toxic form.

An important factor to consider in the behaviour of chiral drugs in soil is temperature. Previous drug degradation studies have utilised soil temperatures in the range $18-25{ }^{\circ} \mathrm{C}$ (Monteiro and Boxall, 2009; Xu et al., 2009; Carr et al., 2011; Lin and Gan, 2011; Grossberger et al., 2014; Petrie et al., 2018). In temperate climates such as the United Kingdom (UK), average monthly soil temperatures generally vary from $4{ }^{\circ} \mathrm{C}$ in winter to $18{ }^{\circ} \mathrm{C}$ in summer (Busby, 2015), depending on location. Soil temperature had a significant impact on degradation of the herbicide florasulam (Krieger et al., 2000). Florasulam $t_{1 / 2}$ was found to be $8.5 \mathrm{~d}$ at $20{ }^{\circ} \mathrm{C}$ and $85 \mathrm{~d}$ at $5{ }^{\circ} \mathrm{C}$ in a clay loam soil. Thus, soil temperature is likely to play a considerable role in the degradation of pharmaceuticals, and their enantiomeric composition. 
78 Due to the lack of research undertaken on the enantioselectivity of chiral drugs in soil, the objectives of 79 this study were to: (i) investigate the enantiospecific behaviour of a diverse range of chiral drugs in soil, 80 (ii) establish the influence of temperate summer $\left(18^{\circ} \mathrm{C}\right)$ and winter $\left(4^{\circ} \mathrm{C}\right)$ soil temperatures on chiral 81 drug degradation and (iii) determine the processes responsible for enantioselective drug transformation 82 (i.e., selective enantiomer degradation or chiral inversion). To achieve this, the fate of a chemically 83 diverse selection of chiral drugs with one chiral centre (naproxen, ibuprofen, salbutamol, bisoprolol, 84 metoprolol, propranolol, acebutolol, atenolol, chlorpheniramine, amphetamine, fluoxetine and 85 citalopram - Table S1) was investigated in soil microcosms. Data from this work will improve our 86 understanding and prediction of the risks associated with chiral pharmaceutical drugs in amended soils. 


\section{Materials and methods}

\subsection{Materials}

Methanol, ammonium acetate, acetic acid and ammonium formate were HPLC grade and obtained from Sigma Aldrich. The reference materials $R / S( \pm)$-naproxen, $R(-)$-naproxen, $S(+)$-naproxen, $R / S( \pm)$ ibuprofen, $R(-)$-ibuprofen, $S(+)$-ibuprofen, $R / S( \pm)$-salbutamol, $R / S( \pm)$-bisoprolol, $R / S( \pm)$-metoprolol, $R / S( \pm)$-amphetamine, $S(+)$-amphetamine, $R(-)$-amphetamine, $R / S( \pm)$-propranolol, $R / S( \pm)$-acebutolol, $R / S( \pm)$-fluoxetine, $R / S( \pm)$-atenolol, $R(+)$-atenolol, $S(-)$-atenolol $R / S( \pm)$-chlorpheniramine, and $R / S( \pm)$ citalopram were purchased from Sigma Aldrich (Gillingham, UK) and Toronto Research Chemicals (Toronto, Canada). The corresponding deuterated surrogates were also purchased as racemates: $R / S( \pm)$ -

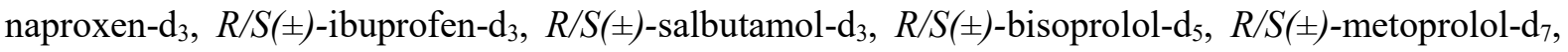

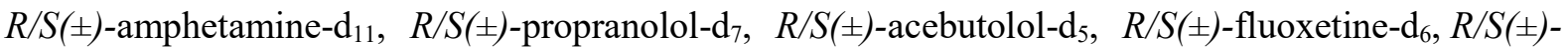
atenolol- $\mathrm{d}_{7}, R / S( \pm)$-chlorpheniramine- $\mathrm{d}_{6}$, and $R / S( \pm)$-citalopram- $\mathrm{d}_{6}$. All chemicals were purchased as methanolic solutions of $0.1 \mathrm{mg} \mathrm{mL}^{-1}$ or $1 \mathrm{mg} \mathrm{mL}^{-1}$, or as powder. Powders were prepared at an appropriate concentration in methanol. All solutions were stored in the dark at $-20^{\circ} \mathrm{C}$. Oasis $\mathrm{HLB}$ cartridges (3cc 60mg) were purchased from Waters (Manchester, UK).

\subsection{Soil microcosms}

Microcosm studies were performed to investigate drug degradation in soil under biotic and abiotic conditions. Soil ( $\sim 5 \mathrm{~kg})$ was collected from an arable farm in North-East Scotland during February 2019 (Table S2). The field where soil was collected had not been treated with biosolids or animal manure for the past five years. Consequently, no background levels of any of the studied drugs were found. Sample collection consisted of pooling randomly collected $10 \mathrm{~g}$ grab samples from a $20,000 \mathrm{~m}^{2}$ area. Sub-samples were collected at least $10 \mathrm{~m}$ from the field boundary and from the top $10 \mathrm{~cm}$ surface layer of the soil. Soil was transferred to the laboratory immediately and sieved to less than $2 \mathrm{~mm}$. To achieve abiotic conditions, $500 \mathrm{~g}$ of the sieved soil was autoclaved three times. Sodium azide was then added to soil at a concentration of $200 \mu \mathrm{g} \mathrm{g}^{-1}$ as described by Grossberger et al (2014).

Sacrificial microcosms were utilised in this study and prepared in a laminar flow cabinet. For both biotic and abiotic microcosms, $5 \mathrm{~g}$ of the corresponding soil was added to $50 \mathrm{~mL}$ sterile polypropylene tubes. 
24 tubes were prepared for each treatment condition enabling eight different sampling times (triplicate extractions). Soils were left for $12 \mathrm{~h}$ at the treatment temperature prior to spiking with drugs. Tubes were spiked with racemic drugs at concentrations of either $100 \mathrm{ng} \mathrm{g}^{-1}$ (high spike) or $10 \mathrm{ng} \mathrm{g}^{-1}$ (low spike). All spiked and measured concentrations are reported as wet weight (e.g., ng g ${ }^{-1}$ wet weight). Both racemic naproxen and ibuprofen were spiked at 10,000 $\mathrm{ng} \mathrm{g}^{-1}$ (high) and 1,000 $\mathrm{ng} \mathrm{g}^{-1}$ (low) to reflect their higher concentration in biosolids and the environment (Radjenović et al., 2009; Albero et al., 2014; Petrie et al., 2015). Spiking was achieved using $500 \mu \mathrm{L}$ of an aqueous working solution $(<2$ $\%$ methanol) of all drugs at their appropriate concentration. Biotic microcosms were incubated at both $18{ }^{\circ} \mathrm{C}$ and $4{ }^{\circ} \mathrm{C}$ for both high and low spike levels. Abiotic microcosms (high and low spike level) were incubated at $18{ }^{\circ} \mathrm{C}$. To ensure abiotic microcosms remained sterile throughout the study, aqueous soil extracts were inoculated on Petri dishes containing $1.5 \%$ agar medium. All microcosms were kept in the dark throughout the study. For biotic microcosms, their weight was adjusted with water every few days to maintain their field moisture content of $26 \%$. Triplicate samples were collected at times 0,1 , $3,7,14,28,42$ and 56 days ready for analysis by accelerated solvent extraction-solid phase extractionliquid chromatography-tandem mass spectrometry (ASE-SPE-LC-MS/MS).

Further biotic microcosms were prepared using single enantiomers to help understand enantioselective transformation processes. These were prepared using the same soil, albeit following storage at $4{ }^{\circ} \mathrm{C}$ for $60 \mathrm{~d}$ (moisture content was adjusted to field conditions prior to initiating the microcosms). Microcosms were spiked at the high level $\left(5,000 \mathrm{ng} \mathrm{g}^{-1}\right.$ in the case of naproxen and ibuprofen or $50 \mathrm{ng} \mathrm{g}^{-1}$ for amphetamine and atenolol, respectively for individual enantiomers) with either $S(+)$-naproxen, $S(+)$ ibuprofen, $S(+)$-amphetamine and $R(+)$-atenolol, or $R(-)$-naproxen, $R(-)$-ibuprofen, $R(-)$-amphetamine and $S(-)$-atenolol. The same methodology as described for the racemic microcosms was followed. A summary of all microcosms prepared was outlined (Figure S1).

\subsection{Soil extraction}

Soil samples ( $5 \mathrm{~g}$ ) were spiked with a methanolic mixture of all racemic deuterated surrogates to achieve a concentration of $100 \mathrm{ng} \mathrm{g}^{-1}\left(10,000 \mathrm{ng} \mathrm{g}^{-1}\right.$ in the case of $R / S( \pm)$-naproxen- $\mathrm{d}_{3}$ and $R / S( \pm)$-ibuprofen- $\left.\mathrm{d}_{3}\right)$. Samples were mixed with Ottawa sand and packed into $10 \mathrm{~mL}$ stainless steel ASE cells. Two 2-4 $\mu \mathrm{m}$ 
Dionex glass fibre filters were fitted to each end of the cell. The extraction of prepared soil samples was

142 performed using a Dionex ASE-350 system (California, USA). The final method used an extraction 143 solvent of 20:80 water:methanol and an extraction temperature of $80{ }^{\circ} \mathrm{C}$ as described in Petrie et al.

144 (2018). Briefly, two extractions cycles were performed for each sample with the following settings: preheat for $5 \mathrm{~min}$, heating for $5 \mathrm{~min}$, solvent flush volume of $60 \%$ and nitrogen purge time of $150 \mathrm{~s}$. The extraction pressure was 1500 psi.

Solvent extracts obtained from the ASE ( $\sim 22 \mathrm{~mL})$ were diluted to $250 \mathrm{~mL}$ using HPLC water. Oasis HLB cartridges were conditioned with $2 \mathrm{~mL}$ methanol followed by $2 \mathrm{~mL}$ water under gravity. Samples were then loaded at $5 \mathrm{~mL} \mathrm{~min}{ }^{-1}$ using a vacuum manifold and dried under vacuum. Analytes were eluted under gravity using a $4 \mathrm{~mL}$ aliquot of methanol. Extracts were dried at $40{ }^{\circ} \mathrm{C}$ under nitrogen and reconstituted in $0.5 \mathrm{~mL}$ methanol for LC-MS/MS analysis.

\subsection{Enantioselective liquid chromatography-tandem mass spectrometry}

Chromatography was performed using an Agilent 1260 Infinity Series HPLC. Two methods were utilised for the separation of a full suite of analytes. For the separation of naproxen and ibuprofen a CHIRAL ART Amylose-SA column $(250 \times 4.6 \mathrm{~mm} ; 5 \mu \mathrm{m})\left(\mathrm{YMC}\right.$, Kyoto, Japan) maintained at $25^{\circ} \mathrm{C}$ was used. The mobile phase consisted of 30:70 water:methanol containing $10 \mathrm{mM}$ ammonium formate adjusted to $\mathrm{pH} 3.5$ using formic acid. The flow rate was $0.8 \mathrm{~mL} \mathrm{~min}^{-1}$ with an injection volume of 20 $\mu \mathrm{L}$. The run time was $20 \mathrm{~min}$. All remaining drugs were separated using a Chirobiotic V2 column (250 $\times 2.1 \mathrm{~mm} ; 5 \mu \mathrm{m})\left(\right.$ Supelco, Sigma Aldrich) maintained at $15{ }^{\circ} \mathrm{C}$ (Ramage et al., 2019). The mobile phase was methanol containing $1 \mathrm{mM}$ ammonium acetate and $0.01 \%$ acetic acid at a flow rate of 0.17

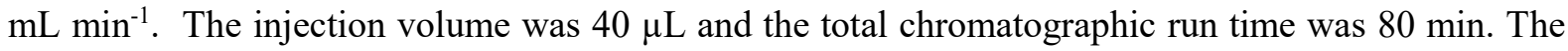
HPLC was coupled to an Agilent $6420 \mathrm{MS} / \mathrm{MS}$ triple quadrupole by electro-spray ionisation (ESI) in positive ionization mode. Selective ion monitoring transitions were utilised for naproxen and ibuprofen. All remaining drugs were analysed by multiple reaction monitoring. All monitored transitions can be found in Table S3. Example chromatograms can be found in Figure S2. Method quantitation limits were in the range 18-134 $\mathrm{ng} \mathrm{g}^{-1}$ for naproxen and ibuprofen, and $\leq 1.3 \mathrm{ng} \mathrm{g}^{-1}$ for all remaining drugs (Table S4). 
169 Enantiomeric fraction (EF) of each drug was calculated according to eq 1:

$170 \quad E F=\frac{E(+)}{[E(+)+E(-)]}$

$171 E(+)$ and $E(-)$ is the concentration of the + and - enantiomers, respectively. Where the enantiomer 172 elution order is unknown the EF was calculated using eq 2:

$173 \quad E F=\frac{E 1}{[E 1+E 2]}$

174 Here, $E 1$ is the first eluting enantiomer and $E 2$ is the second eluting enantiomer. The EF can vary from 1750 to 1 and an EF of 0.5 denotes an equimolar or racemic mixture of enantiomers.

176 Drug degradation was fitted to the first-order exponential decay model using eq 3:

$177 C_{t}=C_{0} x e^{-k t}$

178 Here, $C_{t}$ is the drug concentration at time $t(\mathrm{~d})$ and $C_{0}$ is the drug concentration at the start of the study,

179 and $k$ is the degradation rate constant $(1 / d)$. Furthermore, drug half-life $\left(t_{1 / 2}\right)$ was calculated according 180 to eq $4:$

$181 \quad t_{1 / 2}=\frac{\ln (2)}{k}$ 


\section{Results and discussion}

\subsection{Enantiospecific behaviour of a diverse range of chiral drugs in soil}

The enantiomeric composition of chiral drugs was monitored in biotic and abiotic soil microcosms spiked with racemic drug standards. All drugs were investigated simultaneously. These results are grouped and presented according to therapeutic drug group.

\subsubsection{Anti-inflammatories}

The anti-inflammatory drugs naproxen and ibuprofen are among the most well studied drugs in soils albeit not at the enantiomeric level (Monteiro and Boxall, 2009; Xu et al., 2009; Carr et al., 2011; Lin and Gan, 2011; Grossberger et al., 2014). In soil microcosms $R / S( \pm)$-naproxen degraded under biotic conditions at $18{ }^{\circ} \mathrm{C}$ (Figure 1). In the high spike microcosm $\left(10,000 \mathrm{ng} \mathrm{g}^{-1}\right)$, the starting EF of $0.52 \pm 0.01$ was increased to $0.67 \pm 0.01$ after $56 \mathrm{~d}$ incubation representing an enrichment of $S(+)$-naproxen. Enantiomer $t_{1 / 2}$ values were $9.7 \pm 0.3$ and $11.8 \pm 0.4 \mathrm{~d}$ for $S(+)$-naproxen and $R(-)$-naproxen, respectively (p-value $<0.05)$ (Table 1). Interestingly, enantiomer degradation was greater at the low spike level $\left(1,000 \mathrm{ng} \mathrm{g}^{-1}\right)$ with $t_{1 / 2}$ values of $6.9 \pm 0.8$ and $7.8 \pm 0.5 \mathrm{~d}$ for $S(+)$-naproxen and $R(-)$-naproxen. For the low spike level, a maximum EF of $0.66 \pm 0.04$ was observed (Figure 1). Significantly different $t_{1 / 2}$ values were observed between high and low spike microcosms ( $\mathrm{p}$-values $<0.05)$ and is in agreement with Grossberger et al (2014). This observation was apparent for most studied drugs (Table 1). However, the first-order decay model is concentration independent (Alexander, 1999), suggesting the need for a pseudo second-order model (Grossberger et al., 2014). Nevertheless, for comparison between enantiomers of the same drug and published data, the first-order decay model was applied. Literature $t_{1 / 2}$ values range from $3 \mathrm{~d}$ to $69 \mathrm{~d}$ under a range of different experimental conditions (Monteiro and Boxall, 2009; Xu et al., 2009; Lin and Gan, 2011; Grossberger et al., 2014).

$R / S\left( \pm\right.$ )-ibuprofen degraded rapidly in biotic microcosms at $18{ }^{\circ} \mathrm{C}$ with enantiomer $t_{1 / 2}$ values of $1.0-2.3$ d (Figure S4). Although previous studies do not report ibuprofen at the enantiomeric level, whole drug studies report $t_{1 / 2}$ values ranging from $<1 \mathrm{~d}$ to $15 \mathrm{~d}$ (Monteiro and Boxall, 2009; Xu et al., 2009; Lin and Gan, 2011; Grossberger et al., 2014). An enrichment of $R$ (-)-ibuprofen was observed resulting in EF 
values reaching 0.38-0.39 after $3 \mathrm{~d}$ incubation. This is in agreement with Hashim et al (2011) who report racemic ibuprofen becoming enriched with $R(-)$-ibuprofen during wastewater treatment.

Abiotic microcosms were prepared to confirm drug degradation in soil is biologically driven. Sterile conditions were confirmed by the absence of any colony forming units in inoculated agar medium (Figure S3). In abiotic microcosms, no significant degradation of naproxen or ibuprofen, or changes to their EF were observed during the $56 \mathrm{~d}$ incubation time at either concentration level (Figure 1, Figure S4), confirming their enantioselective transformation is a result of biological processes. Indeed, no degradation or changes to the enantiomeric composition of any studied drug were found in abiotic conditions. The absence of any drug degradation in abiotic soils is in agreement with previous studies (Lin and Gan, 2011; Grossberger et al., 2014).

In soil incubated at $4{ }^{\circ} \mathrm{C}$ naproxen enantiomer degradation was reduced significantly, and by 6.2 to 9.2 times at the high spike level (p-value $<0.05$ ). To demonstrate, the $S(+)$-naproxen $t_{1 / 2}$ of $11.8 \pm 0.4 \mathrm{~d}$ at 18 ${ }^{\circ} \mathrm{C}$ was increased to $109 \pm 12.1 \mathrm{~d}$ at $4{ }^{\circ} \mathrm{C}$ (Table 1$)$. Here, enantiomeric changes were still observed within the $56 \mathrm{~d}$ incubation time. The starting EF of $0.48 \pm 0.01$ increased to $0.55-0.56$ from $28 \mathrm{~d}$ onwards (Figure 1). At the low spike level, 4.4 to 8.2 times reduced degradation was found (p-value $<0.05$ ). The greatest EF was observed after $56 \mathrm{~d}$ where the EF was $0.70 \pm 0.03$ (Figure 1). Soil incubation temperatures of 4 ${ }^{\circ} \mathrm{C}$ saw ibuprofen $t_{1 / 2}$ values increase by up to 2.7 times (Table 1 ). However, no change to $R(-)$-ibuprofen $t_{1 / 2}$ was noted in the low spike microcosms. A minimum EF of $0.43 \pm 0.06$ was found here after $3 \mathrm{~d}$. EFs of 0.38-0.39 were observed in the high spike microcosms, albeit at days 7 and 14 (Figure S4). Although temperature had a significant effect on naproxen and ibuprofen degradation, less impact was found at the lower concentration level. Previous soil microcosm studies report reduced nitrification kinetics (Tourna et al., 2008) and respiration rates (measured through $\mathrm{CO}_{2}$ production) (Andrews et al., 2010) in soils incubated at temperatures $\leq 10{ }^{\circ} \mathrm{C}$.

\subsubsection{Anti-histamine}

Chlorpheniramine is an over the counter antihistamine previously prioritised as a drug for further study in the environment (Boxall, 2004). Research has found it to be incompletely removed during wastewater 
treatment (Roberts et al., 2016), yet there is still a paucity of information on its environmental fate. Chlorpheniramine is moderately hydrophobic $\left(\log K_{O W} 3.67\right)$ suggesting it is likely to partition into wastewater sludge. In soil microcosms no notable degradation ( $>20 \%)$ of $R / S( \pm)$-chlorpheniramine, or changes to its enantiomeric composition were observed in any of the biotic microcosms (Figure S5). Previous studies prepared under similar conditions using the same drug concentration (albeit with different soil) showed $>50 \%$ degradation over $56 \mathrm{~d}$ (Petrie et al., 2018). This difference in degradation is attributed to differences in microbial community of the collected soils. However, further work is required to confirm this assumption.

\subsubsection{Beta-blockers and beta-agonist}

Beta-blockers showed a range of behaviour in soil microcosms. $R / S( \pm)$-bisoprolol, $R / S( \pm)$-metoprolol and $R / S( \pm$ )-propranolol all degraded without enantioselective transformation (Figure S6-8). Enantiomer $t_{1 / 2}$ values at $18{ }^{\circ} \mathrm{C}$ for the high spike level (100 $\left.\mathrm{ng} \mathrm{g}^{-1}\right)$ were 19-20 d, 61-64 $\mathrm{d}$ and 91-106 d, respectively (Table 1). $R / S( \pm)$-propranolol behaviour is similar to that observed previously (Petrie et al., 2018). No previous data exists on the enantiospecific behaviour of bisoprolol and metoprolol in soil. However, metoprolol has shown enantioselective degradation in river waters (Evans et al., 2017).

$R / S( \pm)$-atenolol was found to degrade rapidly with enantiomer $t_{1 / 2}$ values in the range $3.6-8.0 \mathrm{~d}$ at $18{ }^{\circ} \mathrm{C}$ and 6.0-15.6 d at $4{ }^{\circ} \mathrm{C}$ (Table 1). An enrichment of $S(-)$-atenolol was observed with EFs reaching a minimum of $0.36 \pm 0.10$ after $7 \mathrm{~d}$ in the low spike microcosm $\left(10 \mathrm{ng} \mathrm{g}^{-1}\right)$ at $18{ }^{\circ} \mathrm{C}$ (Figure S9). This agrees with previous work in agricultural soil (Petrie et al., 2018), with the same enrichment pathway also found in wastewater (Nikolai et al., 2006; Kasprzyk-Hordern and Baker, 2012; Evans et al., 2017). Enrichment of $S(-)$-atenolol is significant as this enantiomer has greater potency and is found to be about four times more toxic than $R(+)$-atenolol to the environmental toxicity indicator species Tetrahymena thermophila (de Andrés et al., 2009).

The enantiospecific behaviour of $R / S( \pm)$-acebutolol has not been investigated in the receiving environment despite it being found in wastewater and surface waters (Daneshvar et al., 2010; GabetGiraud et al., 2014) as well as having a propensity to adsorb to wastewater sludge and sediments (Ramil 
et al., 2010; Sanganyado et al., 2016). In soil, acebutolol-E1 was found to degrade at a comparatively faster rate than acebutolol-E2 (Figure 2). Acebutolol-E1 $t_{1 / 2}$ values were $36.9 \pm 3.9 \mathrm{~d}$ and $33.4 \pm 3.2 \mathrm{~d}$ for the high and low spike levels at $18{ }^{\circ} \mathrm{C}\left(t_{1 / 2}\right.$ values could not be calculated for acebutolol-E2) (Table 1). Minimum EFs were $0.35 \pm 0.01$ (high spike) and $0.32 \pm 0.01$ (low spike) after $56 \mathrm{~d}$ demonstrating the considerable changes in enantiomeric composition of acebutolol found (Figure 2). Based on the work by Sanganyado et al (2016) using a similar chromatographic column and mobile phase conditions where the order of enantiomer elution is known, it is likely the more persistent enantiomer in soil was $R(+)$ acebutolol. This may be significant in the environment as $R(+)$-acebutolol is the active enantiomer and possesses the beta-blocking activity (Piquette-Miller et al., 1991). Interestingly, at $4{ }^{\circ} \mathrm{C}$ there was no degradation of either enantiomer and the drug remained unchanged over $56 \mathrm{~d}$ (Figure 2).

In contrast, the beta-agonist $R / S( \pm)$-salbutamol degraded rapidly with enantiomer $t_{1 / 2}$ values of $\leq 1.2 \mathrm{~d}$ under all biotic conditions, irrespective of temperature (Table 1). A small increase in EF was observed during degradation with an enrichment of salbutamol-E1 (Figure S10). Rapid degradation has been observed previously in soil with complete degradation observed within $14 \mathrm{~d}$ (Petrie et al., 2018).

\subsubsection{Anti-depressants}

Anti-depressants including citalopram and fluoxetine have been determined in biosolids and amended soils previously (Walters et al., 2010; Lajeunesse et al., 2012; Evans et al., 2015). In soil microcosms both $R / S( \pm)$-citalopram and $R / S( \pm)$-fluoxetine did not show any considerable degradation over $56 \mathrm{~d}$ under biotic conditions (Figure S11 and S12), including any changes to their enantiomeric composition. The persistence of fluoxetine in soils has been previously observed (Monteiro and Boxall, 2009; Walters et al., 2010; Petrie et al., 2018). Walters et al (2010) reported no degradation of fluoxetine in soil over $1,000 \mathrm{~d}$.

\subsubsection{Stimulant}

The stimulant amphetamine degraded rapidly and enantioselectively in biotic microcosms (Figure S13). Enrichment with $R(-)$-amphetamine was considerable with EFs $<0.2$ after $3 \mathrm{~d}$. This observation is consistent with previous studies demonstrating greater persistence of $R(-)$-amphetamine in the 
environment (Bagnall et al., 2013; Evans et al., 2017), including soil (Petrie et al., 2018). This may be significant as $S(+)$-amphetamine has twice the stimulant activity of $R(-)$-amphetamine (KasprzykHordern, 2010). However, enantiospecific toxicity towards environmental organisms is yet to be established. Nevertheless, complete enantiomer degradation was observed within $28 \mathrm{~d}$ at $18{ }^{\circ} \mathrm{C}$ and within $42 \mathrm{~d}$ at $4{ }^{\circ} \mathrm{C}$ (Figure S13).

\subsection{Transformation processes responsible for enantiospecific drug changes}

Individual enantiomer microcosms were prepared to identify the processes responsible for enantiospecific transformations (Figure S1). The drugs studied were naproxen, ibuprofen, atenolol and amphetamine as they were subject to the greatest enantiomeric changes in racemic microcosms (acebutolol could not be obtained as individual enantiomers at the time of the study).

At $18{ }^{\circ} \mathrm{C}$ the loss of $R(-)$-naproxen coincided with the formation of $S(+)$-naproxen through chiral inversion (Figure 3). The EF changed from an initial value of 0.00 to $0.54 \pm 0.02$ after $28 \mathrm{~d}$. On the other hand, the loss of $S(+)$-naproxen from its respective microcosm resulted in the formation of $R(-)$ naproxen. In this case an initial EF of 1.00 changed to $0.78 \pm 0.01$ after $28 \mathrm{~d}$ (Figure 3). However, as both inversion and degradation are taking place, it remains unknown which process (or both) is responsible for the overall changes in enantiomeric composition observed in racemic microcosms previously. Nevertheless, this is the first-time chiral inversion of a drug has been reported in soil, and that it can proceed in both directions. Chiral inversion of $S(+)$-naproxen to $R(-)$-naproxen has been observed previously during wastewater treatment (Hashim et al., 2011; Suzuki et al., 2014). Furthermore, Nguyen et al (2017) reported bidirectional inversion of anti-inflammatories (naproxen, ibuprofen and ketoprofen) by an enzymatic membrane bioreactor. The results of the single enantiomer microcosms agree with those of the racemic microcosm whereby an enrichment of $S(+)$-naproxen was found (Figure 1). Incubation of soil at $4{ }^{\circ} \mathrm{C}$ resulted in little or no inversion of naproxen enantiomers (Figure 3). 
Ibuprofen enantiomers were also inverted in soil microcosms (Figure S14). Enrichment was preferential towards $R(-)$-ibuprofen (pharmacologically inactive enantiomer) resulting in those $\mathrm{EFs}<0.5$ found in racemic microcosms previously (Figure S4). For example, incubation at $4{ }^{\circ} \mathrm{C}$ resulted in EF changes from 0.00 to $0.28 \pm 0.02$ in the $R(-)$-ibuprofen spiked microcosm and from 1.00 to $0.48 \pm 0.03$ in the $S(+)$ ibuprofen spiked microcosm over $56 \mathrm{~d}$ (Figure S14). In vivo mammalian studies have reported unidirectional conversion of $R(-)$-ibuprofen to $S(+)$-ibuprofen (Hao et al., 2005). Similarly, fungi such as Verticillium lecanii have been found to preferentially convert $R(-)$-ibuprofen to $S(+)$-ibuprofen by an enzymatic process related to mammalian studies (Thomason et al., 1998). However, evidence reporting the inversion of $S(+)$-ibuprofen to $R(-)$-ibuprofen by Nocardia bacteria exists (Mitsukura et al., 2002), as well as in lake water microcosms (Buser et al., 1999) and during wastewater treatment (Nguyen et al., 2017). The mechanism of chiral inversion remains poorly understood, particularly in the environment, but it is believed several enzymes play a role (Kato et al., 2003; Kato et al., 2004; Khan et al., 2014). It is thought that S-enantiomers form an activated coenzyme A derivative followed by epimerization to the $R$-enantiomer and hydrolysis of the $R$-acyl-coenzyme (Khan et al., 2014). Essentially, following an enzyme mediated deprotonation from the stereogenic centre an intermediate compound with a $\mathrm{c}=\mathrm{c}$ double bond is formed. A subsequent (re)protonation can then take place either side of the $\mathrm{c}=\mathrm{c}$ resulting in the formation of the antipode.

Degradation of atenolol enantiomers showed enantioselective degradation with $t_{1 / 2}$ values of $5.0 \pm 0.4$ and 3.4 $\pm 0.1 \mathrm{~d}$ for $S(-)$-atenolol and $R(+)$-atenolol at $18{ }^{\circ} \mathrm{C}$, respectively (p-value $<0.05$ ) (Figure $\mathrm{S} 15$ ). No evidence of chiral inversion (or changes to EF) was observed. The comparatively faster degradation of $R(+)$-atenolol confirms the enrichment of $S(-)$-atenolol $(\mathrm{EF}<0.5)$ observed in racemic microcosms previously (Figure S9). However, the degradation rates were significantly different between the single enantiomer and racemic microcosms. Greatest differences were observed for soils incubated at $4{ }^{\circ} \mathrm{C}$. For example, in racemic microcosms the $t_{1 / 2}$ value of $S(-)$-atenolol was $15.6 \pm 0.6 \mathrm{~d}$ and in single enantiomer microcosms it was $35.5 \pm 3.7 \mathrm{~d}$ (p-value $<0.05$ ). Although the same soil was used in both studies, soil was stored for $60 \mathrm{~d}$ at $4{ }^{\circ} \mathrm{C}$ prior to initiation of the single enantiomer microcosms. While this satisfies accepted guidelines (OECD, 2002), the differences in post-sampling storage is likely to 
account for this. Stenberg et al (1998) reported effects on microbial biomass and activities in soils under cold storage. Nevertheless, the transformation processes identified and changes to EF observed correspond to those enantiospecific changes found in racemic microcosms.

Amphetamine enantiomers also showed enantioselective degradation without evidence of inversion (Figure S16). The $t_{1 / 2}$ values were $1.0 \pm 0.2 \mathrm{~d}$ for $S(+)$-amphetamine and $2.3 \pm 0.0 \mathrm{~d}$ for $R(-)$-amphetamine (p-value $<0.05$ ). To the best of our knowledge this is the first study to confirm the enantioselective degradation of amphetamine and atenolol in the environment (over other enantioselective processes such as chiral inversion) using single enantiomer microcosms.

\subsection{Future perspective on the environmental risk assessment of chiral drugs in soil}

Irrigation of agricultural land with reclaimed wastewater and recycling of biosolids as fertiliser are growing practices. Current environmental risk assessment guidelines for pharmaceuticals drugs in soils do not require enantiospecific toxicity or fate assessments for chiral compounds (European Medicines Agency, 2018). The main reasons for this are (i) there is a lack of information on the enantiomeric composition of drugs in biosolids and irrigation water, as well as their fate in amended soils, and (ii) there are no studies on the enantiospecific toxicity of chiral drugs to terrestrial organisms. Nevertheless, the limited data available for biosolids demonstrating non-racemic composition of drugs being applied to land (Evans et al., 2015), and the extent of enantiomer enrichment in amended soils observed in our study demonstrate studies on enantiospecific toxicity are now needed. Establishing the extent of enantiospecific toxicity towards terrestrial organisms will be a driver for further enantioselective studies of drugs in amended soils.

Care is needed if the analysis of biosolids or irrigation water is used to estimate soil enantiomer concentrations for risk assessment purposes (an approach taken for other trace pollutants (Stasinakis et al., 2008; Petrie et al., 2019). The inversion of pharmacologically less active enantiomers to more active enantiomers in soil or vice versa (e.g., naproxen and ibuprofen - Figure 3, Figure S14) could result in the underestimation or overestimation of risk, respectively (assuming pharmacological activity in 
humans is reflected in environmental toxicity studies). Nevertheless, further fate studies are needed on chiral drugs in amended soils that were out with the scope of this study (different soils, exposure conditions etc) to ensure robust data for risk assessments is obtained. Such investigations need to study the microbial community of studied soils to improve our understanding of chiral drug degradation. It is recommended that laboratory fate studies utilise freshly collected soils to avoid any storage induced effects to the soil microbial community. Risk assessments must also account for soil temperature in fate assessments as it had a considerable impact on chiral drug transformation. For example, application of biosolids as fertiliser in temperate climates is typically done in preparation for spring or winter crop sowing where soil temperatures are notably different.

\section{Conclusions}

This study is the first to evaluate the enantiospecific behaviour of a diverse range of chiral drugs in soil. It found that five of the 12 studied drugs were subject to enantioselective transformation. Both enantioselective degradation (amphetamine and atenolol) and chiral inversion (naproxen and ibuprofen) were identified as transformation processes. Significantly, chiral inversion was found to be bidirectional. Thus, the introduction of the inactive enantiomer to soil can lead to the formation of the active antipode, or vice versa. This observation needs considered in future environmental risk assessments to avoid overestimating or underestimating the associated risks of irrigating agricultural land with reclaimed wastewater, or applying biosolids as fertiliser. However, further studies are now needed on the enantiospecific toxicity of chiral drugs in the terrestrial environment.

\section{Acknowledgements}

The Carnegie Trust for the Universities of Scotland is acknowledged for financial support. The authors wish to thank Crawford Scientific LTD and YMC CO., LTD for the provision of CHIRAL ART columns and analytical support. 


\section{Supplementary material}

392 Additional information includes the experimental set up (Figure S1), example chromatograms (Figure

393 S2) comparison of biotic and abiotic soils inoculated on agar plates (Figure S3), degradation of various

394 chiral drugs in soils as racemates (Figure S4-13) and single enantiomers (Figure S14-16), chemical

395 properties of studied drugs (Table S1), properties of collected soil (Table S2), mass spectrometry 396 information (Table S3) and method performance data (Table S4).

397 
Albero, B., Sánchez-Brunete, C., Miguel, E., Aznar, R., Tadeo, J.L. Determination of selected pharmaceutical compounds in biosolids by supported liquid extraction and gas chromatographytandem mass spectrometry. $J$. Chromatogr. A 2014, 1336, 52-58. DOI: 10.1016/j.chroma.2014.02.020

Alexander, M. Bioremediation and Biodegradation. 1999 In: Focus, second ed. Academic Press, San Diego, California, USA.

Andrews, J.A., Matamala, R., Westover, K.M., Schlesinger, W.H. Temperature effects on the diversity of soil heterotrophs and the $\delta^{13} \mathrm{C}$ of soil-respired $\mathrm{CO}_{2}$. Soil Biol. Biochem. 2000, 32, 699-706. DOI: 10.1016/S0038-0717(99)00206-0

Bagnall, J., Malia, L., Lubben, A., Kasprzyk-Hordern, B. Stereoselective biodegradation of amphetamine and methamphetamine in river microcosms. Water Res. 2013, 47 (15), 5708-5718. DOI: $10.1016 /$ j.watres.2013.06.057

Boxall, A.B.A. The environmental side effects of medication. EMBO Reports 2004, 5 (12), 1110-1116. DOI: $10.1038 /$ sj.embor.7400307

Busby, J. UK shallow ground temperatures for ground coupled heat exchangers. 2015, available from: https://core.ac.uk/download/pdf/33453718.pdf Accessed 9/10/19

Buser, H.-R., Poiger, T., Muller, M.D. Occurrence and environmental behavior of the chiral pharmaceutical drug ibuprofen in surface waters and in wastewater Environ. Sci. Technol. 1999, 33 (15), 2529-2535. DOI: 10.1021/es981014w

Carr, D.L., Morse, A.N., Zak, J.C., Anderson, T.A. Microbially mediated degradation of common pharmaceuticals and personal care products in soil under aerobic and reduced oxygen conditions. Water Air Soil Pollut. 2011, 216 (1-4), 633-642. DOI: 10.1007/s11270-010-0558-y

Daneshvar, A., Svanfelt, J., Kronberg, L., Prévost, M., Weyhenmeyer, G.A. Seasonal variations in the occurrence and fate of basic and neutral pharmaceuticals in a Swedish river-lake system. Chemosphere 2010, 80 (3), 301-309. DOI: 10.1016/j.chemosphere.2010.03.060

De Andrés, F., Castañeda, G., Ríos, Á. Use of toxicity assays for enantiomeric discrimination of pharmaceutical substances. Chirality 2009, 21 (8), 751-759. DOI: 10.1002/chir.20675

European Medicines Agency. Guideline on the environmental risk assessment of medicinal products for human use, 2018. Available from: https://www.ema.europa.eu/en/documents/scientificguideline/draft-guideline-environmental-risk-assessment-medicinal-products-human-userevision-1_en.pdf

Evans, S., Bagnall, J., Kasprzyk-Hordern, B. Enantiomeric profiling of a chemically diverse mixture of chiral pharmaceuticals in urban water. Environ. Pollut. 2017, 230, 368-377. DOI: 10.1016/j.envpol.2017.06.070

Evans, S.E., Davies, P., Lubben, A., Kasprzyk-Hordern, B. Determination of chiral pharmaceuticals and illicit drugs in wastewater and sludge using microwave assisted extraction, solid-phase extraction and chiral liquid chromatography coupled with tandem mass spectrometry. Anal. Chim. Acta 2015, 882, 112-126. DOI: 10.1016/j.aca.2015.03.039

Gabet-Giraud, V., Miège, C., Jacquet, R., Coquery, M. Impact of wastewater treatment plants on receiving surface waters and a tentative risk evaluation: The case of estrogens and beta blockers. Environ. Sci. Pollut. Res. 2014, 21 (3), 1708-1722. DOI: 10.1007/s11356-013-2037-7

Gardner, M., Comber, S., Scrimshaw, M.D., Cartmell, E., Lester, J., Ellor, B. The significance of hazardous chemicals in wastewater treatment works effluents. Sci. Total Environ. 2012, 437, 363 372. DOI: 10.1016/j.scitotenv.2012.07.086 
Grossberger, A., Hadar, Y., Borch, T., Chefetz, B. Biodegradability of pharmaceutical compounds in agricultural soils irrigated with treated wastewater. Environ. Pollut. 2014, 185, 168-177. DOI: 10.1016/j.envpol.2013.10.038

Hao, H., Wang, G., Sun, J., Ding, Z., Wu, X., Roberts, M. Unidirectional inversion of ibuprofen in Caco-2 cells: Developing a suitable model for presystemic chiral inversion study Biol. Pharm. Bull. 2005, 28 (4), 682-687. DOI: 10.1248/bpb.28.682

Hashim, N.H., Nghiem, L.D., Stuetz, R.M., Khan, S.J. Enantiospecific fate of ibuprofen, ketoprofen and naproxen in a laboratory-scale membrane bioreactor. Water Res. 2011, 45 (18), 6249-6258. DOI: $10.1016 /$ j.watres.2011.09.020

Hughes, S.R., Kay, P., Brown, L.E. Global synthesis and critical evaluation of pharmaceutical data sets collected from river systems. Environ. Sci. Technol. 2013, 47 (2), 661-677. DOI: $10.1021 /$ es 3030148

Hutt, A.J., Caldwell, J. The metabolic chiral inversion of 2-arylpropionic acids - a novel route with pharmacological consequences. J. Pharm. Pharmacol. 1983, 35 (11), 693-704. DOI: 10.1111/j.2042-7158.1983.tb02874.x

Kasprzyk-Hordern, B. Pharmacologically active compounds in the environment and their chirality. Chem. Soc. Rev. 2010, 39 (11), 4466-4503. DOI: 10.1039/c000408c

Kasprzyk-Hordern, B., Baker, D.R. Enantiomeric profiling of chiral drugs in wastewater and receiving waters. Environ. Sci. Technol. 2012, 46 (3), 1681-1691. DOI: 10.1021/es203113y

Kato, D., Mitsuda, S., Ohta, H. Microbial deracemization of alpha-substituted carboxylic acids: substrate specificity and mechanistic investigation. J. Organic. Chem. 2003, 68 (19), 7234-7242. DOI: $10.1021 /$ jo034253x

Kato, D., Miyamoto, K., Ohta, H. Microbial deracemization of alpha-substituted carboxylic acids: control of the reaction path. Tetrahedron 2004, 15, 2965-2973. DOI: 10.1016/j.tetasy.2004.06.049

Khan, S.J., Wang, L., Hashim, N.H., McDonald, J.A. Distinct enantiomeric signals of ibuprofen and naproxen in treated wastewater and sewer overflow. Chirality 2014, 26, 739-746. DOI: $10.1002 /$ chir. 22258

Kinney, C.A., Furlong, E.T., Kolpin, D.W., Burkhardt, M.R., Zaugg, S.D., Werner, S.L., Bossio, J.P., Benotti, M.J. Bioaccumulation of pharmaceuticals and other anthropogenic waste indicators in earthworms from agricultural soil amended with biosolid or swine manure. Environ. Sci. Technol. 2008, 42 (6), 1863-1870. DOI: 10.1021/es702304c

Krieger, M.S., Pillar, F., Ostrander, J.A. Effect of temperature and moisture on the degradation and sorption of florasulam and 5-hydroxyflorasulam in soil. J. Agric. Food Chem. 2000, 48 (10), $4757-$ 4766. DOI: $10.1021 / \mathrm{jf000009k}$

Lajeunesse, A., Smyth, S.A., Barclay, K., Sauvé, S., Gagnon, C. Distribution of antidepressant residues in wastewater and biosolids following different treatment processes by municipal wastewater treatment plants in Canada. Water Res. 2012, 46 (17), 5600-5612. DOI: 10.1016/j.watres.2012.07.042

Lin, K., Gan, J. Sorption and degradation of wastewater-associated non-steroidal anti-inflammatory drugs and antibiotics in soils. Chemosphere 201183 (3), 240-246. DOI: 10.1016/j.chemosphere.2010.12.083

Malchi, T., Maor, Y., Tadmor, G., Shenker, M., Chefetz, B. Irrigation of root vegetables with treated wastewater: Evaluating uptake of pharmaceuticals and the associated human health risks. Environ. Sci. Technol. 2014, 48 (16), pp. 9325-9333. DOI: 10.1021/es5017894

Mitsukura, K., Yoshida, T., Nagasawa, T. Synthesis of (R)-2-phenylpropanoic acid from its racemate through an isomerase-involving reaction by Nocardia diaphanozonaria. Biotechnol. Lett. 2002, 24 (19), 1615-1621. DOI: 10.1023/A:1020353631566 
Nguyen, L.N., Hai, F.I., McDonald, J.A., Khan, S.J., Price, W.E., Nghiem, L.D. Continuous transformation of chiral pharmaceuticals in enzymatic membrane bioreactors for advanced wastewater treatment. Water Sci. Technol. 2017, 76 (7), 1816-1826. DOI: 10.2166/wst.2017.331

Nikolai, L.N., McClure, E.L., MacLeod, S.L., Wong, C.S. Stereoisomer quantification of the $\beta$-blocker drugs atenolol, metoprolol, and propranolol in wastewaters by chiral high-performance liquid chromatography-tandem mass spectrometry. J. Chromatogr. A. 2006, 1131 (1-2), 103-109. DOI: 10.1016/j.chroma.2006.07.033

Noguera-Oviedo, K., Aga, D.S. Lessons learned from more than two decades of research on emerging contaminants in the environment. J. Hazard. Mater. 2016, 316, 242-251. DOI: 10.1016/j.jhazmat.2016.04.058

McClellan, K., Halden, R.U. Pharmaceuticals and personal care products in archived U.S. biosolids from the 2001 EPA national sewage sludge survey. Water Res. 2010, 44 (2), 658-668. DOI: 10.1016/j.watres.2009.12.032

Monteiro, S.C., Boxall, A.B.A. Factors affecting the degradation of pharmaceuticals in agricultural soils. Environ. Toxicol. Chem. 2009, 28 (12), 2546-2554. DOI: 10.1897/08-657.1

OECD Guidelines for the testing of chemicals. Test No. 307: Aerobic and anaerobic transformation in soil, 2002. Available from: https://www.oecd-ilibrary.org/environment/test-no-307-aerobic-andanaerobic-transformation-in-soil $9789264070509-$ en;jsessionid=upTqY671UFFGGBjfvvfcIvaR.ip-10-240-5-174

Petrie, B., Barden, R., Kasprzyk-Hordern, B. A review on emerging contaminants in wastewaters and the environment: Current knowledge, understudied areas and recommendations for future monitoring. Water Res. 2015, 72, 3-27. DOI: 10.1016/j.watres.2014.08.053

Petrie, B., Lopardo, L., Proctor, K., Youdan, J., Barden, R., Kasprzyk-Hordern, B. Assessment of bisphenol-A in the urban water cycle. Sci. Total Environ. 2019, 650, 900-907. DOI: 10.1016/j.scitotenv.2018.09.011

Petrie, B., Mrazova, J., Kasprzyk-Hordern, B., Yates, K. Multi-residue analysis of chiral and achiral trace organic contaminants in soil by accelerated solvent extraction and enantioselective liquid chromatography tandem-mass spectrometry. J. Chromatogr. A. 2018, 1572, 62-71. DOI: 10.1016/j.chroma.2018.08.034

Pino, M.R., Val, J., Mainar, A.M., Zuriaga, E., Español, C., Langa, E. Acute toxicological effects on the earthworm Eisenia fetida of 18 common pharmaceuticals in artificial soil. Sci. Total Environ. 2015, 518-519, 225-237. DOI: 10.1016/j.scitotenv.2015.02.080

Piquette-Miller, M., Foster, R.T., Kappagoda, C.T., Jamali, F. Pharmacokinetics of acebutolol enantiomers in humans. J. Pharm. Sci. 1991, 80 (4), 313-316. DOI: 10.1002/jps.2600800405

Radjenović, J., Jelic, A., Petrovic, M., Barcelo, D. Determination of pharmaceuticals in sewage sludge by pressurized liquid extraction (PLE) coupled to liquid chromatography-tandem mass spectrometry (LC-MS/MS). Anal. Bioanal. Chem. 2009, 393, 1685-1695. DOI: 10.1007/s00216009-2604-4

Ramage, S., Camacho-Muñoz, D., Petrie, B. Enantioselective LC-MS/MS for anthropogenic markers of septic tank discharge. Chemosphere 2019, 219, 191-201. DOI: 10.1016/j.chemosphere.2018.12.007

Ramil, M., El Aref, T., Fink, G., Scheurer, M., Ternes, T.A. Fate of beta blockers in aquatic-sediment systems: Sorption and biotransformation. Environ. Sci. Technol. 2010, 44 (3), 962-970. DOI: $10.1021 /$ es 9027452

Roberts, J., Kumar, A., Du, J., Hepplewhite, C., Ellis, D.J., Christy, A.G., Beavis, S.G. Pharmaceuticals and personal care products (PPCPs) in Australia's largest inland sewage treatment plant, and its contribution to a major Australian river during high and low flow. Sci. Total Environ. 2016, 541, 1625-1637. DOI: 10.1016/j.scitotenv.2015.03.145 
Sanganyado, E., Fu, Q., Gan, J. Enantiomeric selectivity in adsorption of chiral $\beta$-blockers on sludge. Environ. Pollut. 2016, 214, 787-794. DOI: 10.1016/j.envpol.2016.04.091

Sanganyado, E., Lu, Z., Fu, Q., Schlenk, D., Gan, J. Chiral pharmaceuticals: A review on their environmental occurrence and fate processes. Water Res. 2017, 124, 527-542. DOI: 10.1016/j.watres.2017.08.003

Stanley, J.K., Ramirez, A.J., Chambliss, C.K., Brooks, B.W. Enantiospecific sublethal effects of the antidepressant fluoxetine to a model aquatic vertebrate and invertebrate. Chemosphere 2007, 69 (1), 9-16. DOI: $10.1016 / j . c h e m o s p h e r e .2007 .04 .080$

Stanley, J.K., Ramirez, A.J., Mottaleb, M., Chambliss, C.K., Brooks, B.W. Enantiospecific toxicity of the $\beta$-blocker propranolol to Daphnia magna and Pimephales promelas. Environ. Toxicol. Chem. 2006, 25 (7), 1780-1786. DOI: 10.1897/05-298R1.1

Stasinakis, A.S., Gatidou, G., Mamais, D., Thomaidis, N.S., Lekkas, T.D. Occurrence and fate of endocrine disrupters in Greek sewage treatment plants. Water Res. 2008, 42 (6-7), 1796-1804. DOI: $10.1016 /$ j.watres.2007.11.003

Stenberg, B., Johansson, M., Pell, M., Sjödahl-Svensson, K., Stenström, J., Torstensson, L. Microbial biomass and activities in soil as affected by frozen and cold storage. Soil Biol. Biochem. 1998, 30 (3), 393-402. DOI: 10.1016/S0038-0717(97)00125-9

Suzuki, T., Kosugi, Y., Hosaka, M., Nishimura, T., Nakae, D. Occurrence and behavior of the chiral anti-inflammatory drug naproxen in an aquatic environment. Environ. Toxicol. Chem. 2014, 33 (12), 2671-2678. DOI: 10.1002/etc.2741

Thomason, M.J., Rhys-Williams, W., Lloyd, A.W., Hanlon, G.W. The stereo inversion of 2arylpropionic acid non-steroidal anti- inflammatory drugs and structurally related compounds by Verticillium lecanii. J. Appl. Microbiol. 1998, 85 (1), 155-163. DOI: 10.1046/j.13652672.1998.00483.x

Tourna, M., Freitag, T.E., Nicol, G.W., Prosser, J.I. Growth, activity and temperature responses of ammonia-oxidizing archaea and bacteria in soil microcosms. Environ. Microbiol. 2008, 10 (5), 1357-1364. DOI: 10.1111/j.1462-2920.2007.01563.x

Walters, E., McClellan, K., Halden, R.U. Occurrence and loss over three years of 72 pharmaceuticals and personal care products from biosolids-soil mixtures in outdoor mesocosms Water Res. 2010, 44 (20), 6011-6020. DOI: 10.1016/j.watres.2010.07.051

Wu, X., Conkle, J.L., Ernst, F., Gan, J. Treated wastewater irrigation: Uptake of pharmaceutical and personal care products by common vegetables under field conditions Environ. Sci. Technol. 2014, 48 (19), 11286-11293. DOI: 10.1021/es502868k

Xu, J., Wu, L., Chang, A.C. Degradation and adsorption of selected pharmaceuticals and personal care products (PPCPs) in agricultural soils, Chemosphere 200977 (10), 1299-1305. DOI: 10.1016/j.chemosphere.2009.09.063 


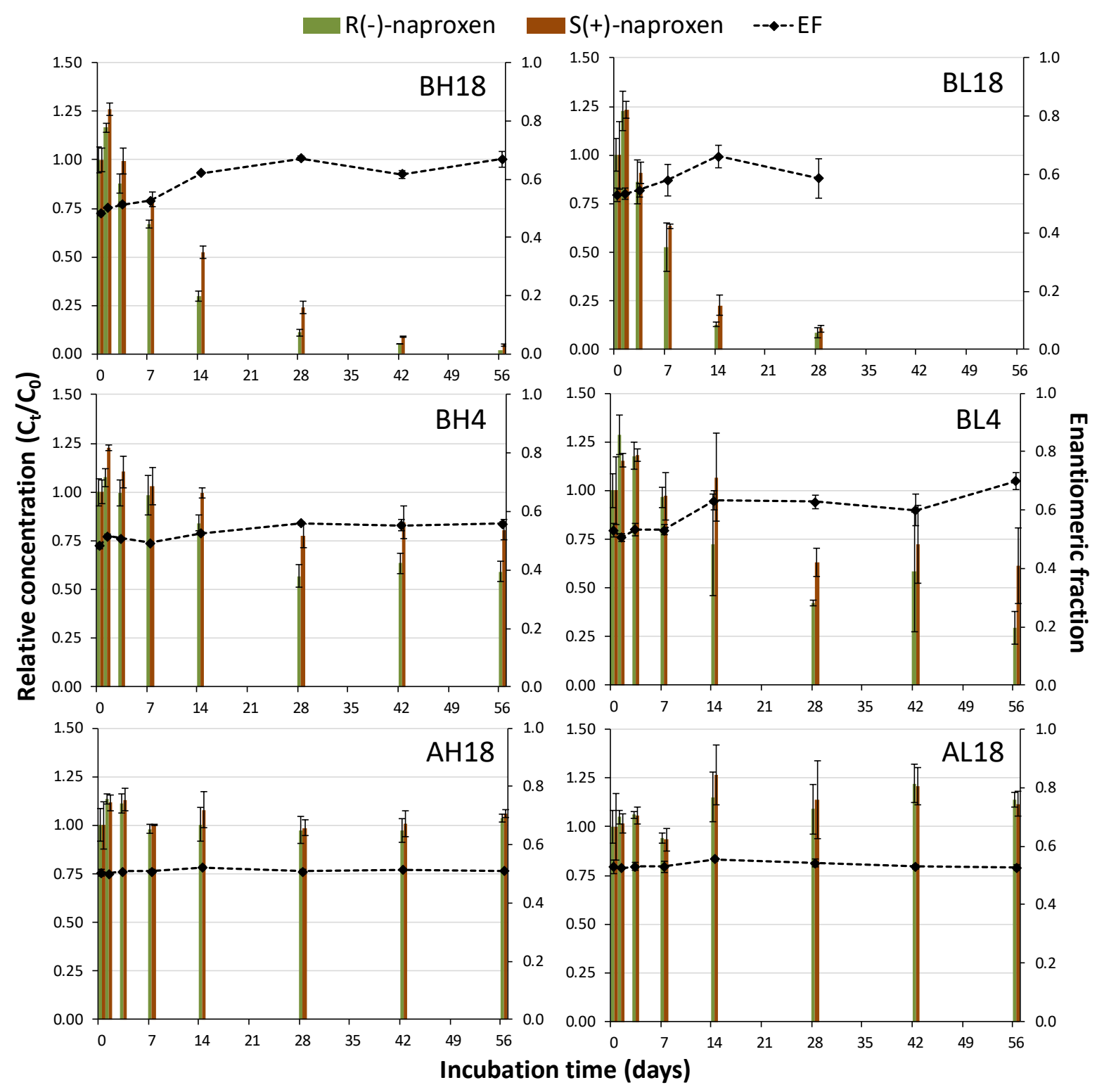

Figure 1. Relative concentration of $R(-)$-naproxen and $S(+)$-naproxen and the corresponding enantiomeric fraction in soil microcosms spiked with racemic $R / S( \pm)$-naproxen

Key: BH18, biotic high spike level $18{ }^{\circ} \mathrm{C}$ microcosm; BL18, biotic low spike level $18{ }^{\circ} \mathrm{C}$ microcosm;

$\mathrm{BH} 4$, biotic high spike level $4{ }^{\circ} \mathrm{C}$ microcosm; BL4 biotic low spike level $4{ }^{\circ} \mathrm{C}$ microcosm; AH18, abiotic high spike level $18{ }^{\circ} \mathrm{C}$ microcosm; AL18, abiotic low spike level $18{ }^{\circ} \mathrm{C}$ microcosm. 


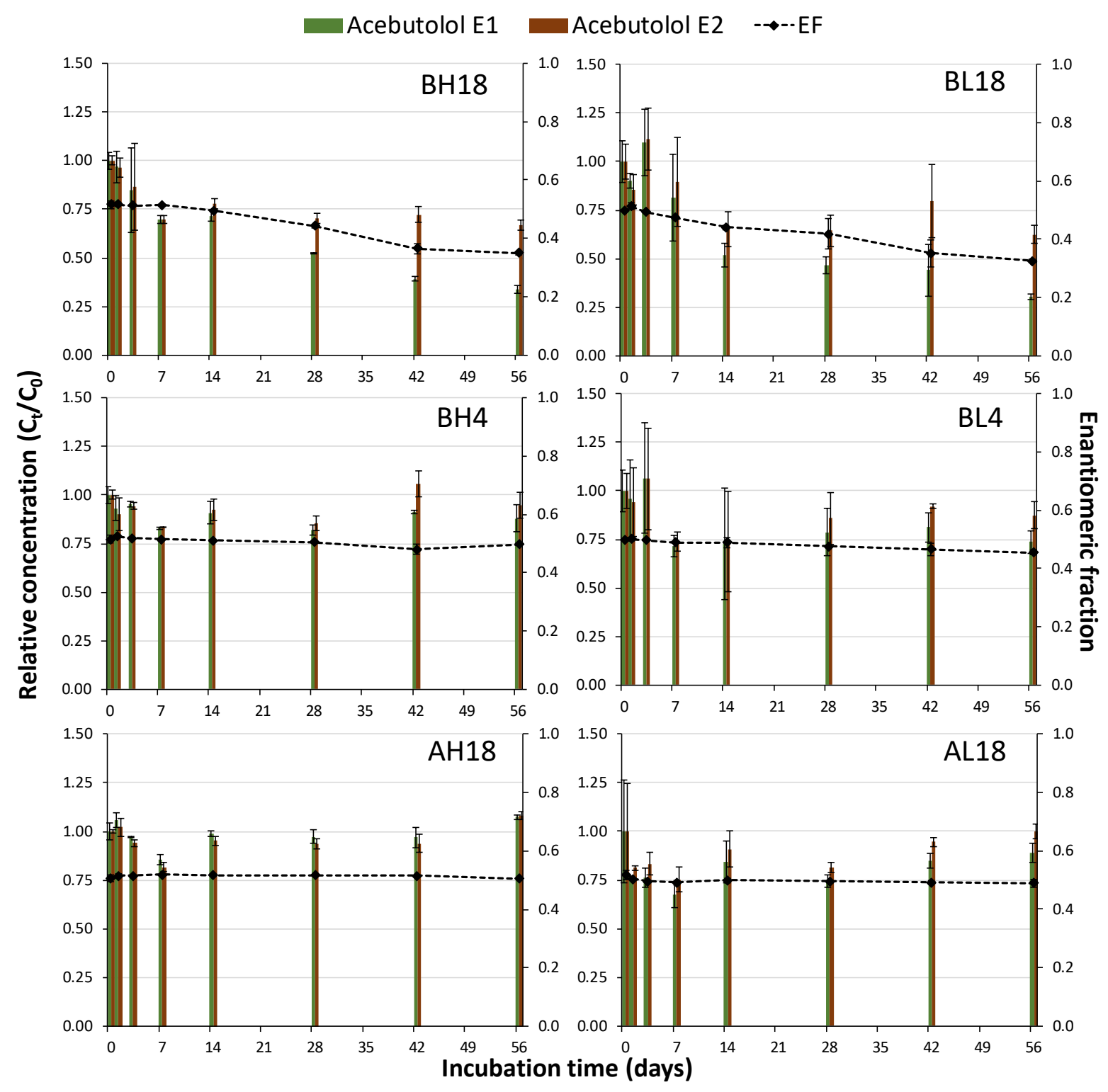

Figure 2. Relative concentration of acebutolol-E1 and acebutolol-E2 and the corresponding enantiomeric fraction in soil microcosms spiked with racemic $R / S( \pm)$-acebutolol

Key: BH18, biotic high spike level $18{ }^{\circ} \mathrm{C}$ microcosm; BL18, biotic low spike level $18{ }^{\circ} \mathrm{C}$ microcosm; BH4, biotic high spike level $4{ }^{\circ} \mathrm{C}$ microcosm; BL4 biotic low spike level $4{ }^{\circ} \mathrm{C}$ microcosm; AH18, abiotic high spike level $18{ }^{\circ} \mathrm{C}$ microcosm; AL18, abiotic low spike level $18{ }^{\circ} \mathrm{C}$ microcosm. 


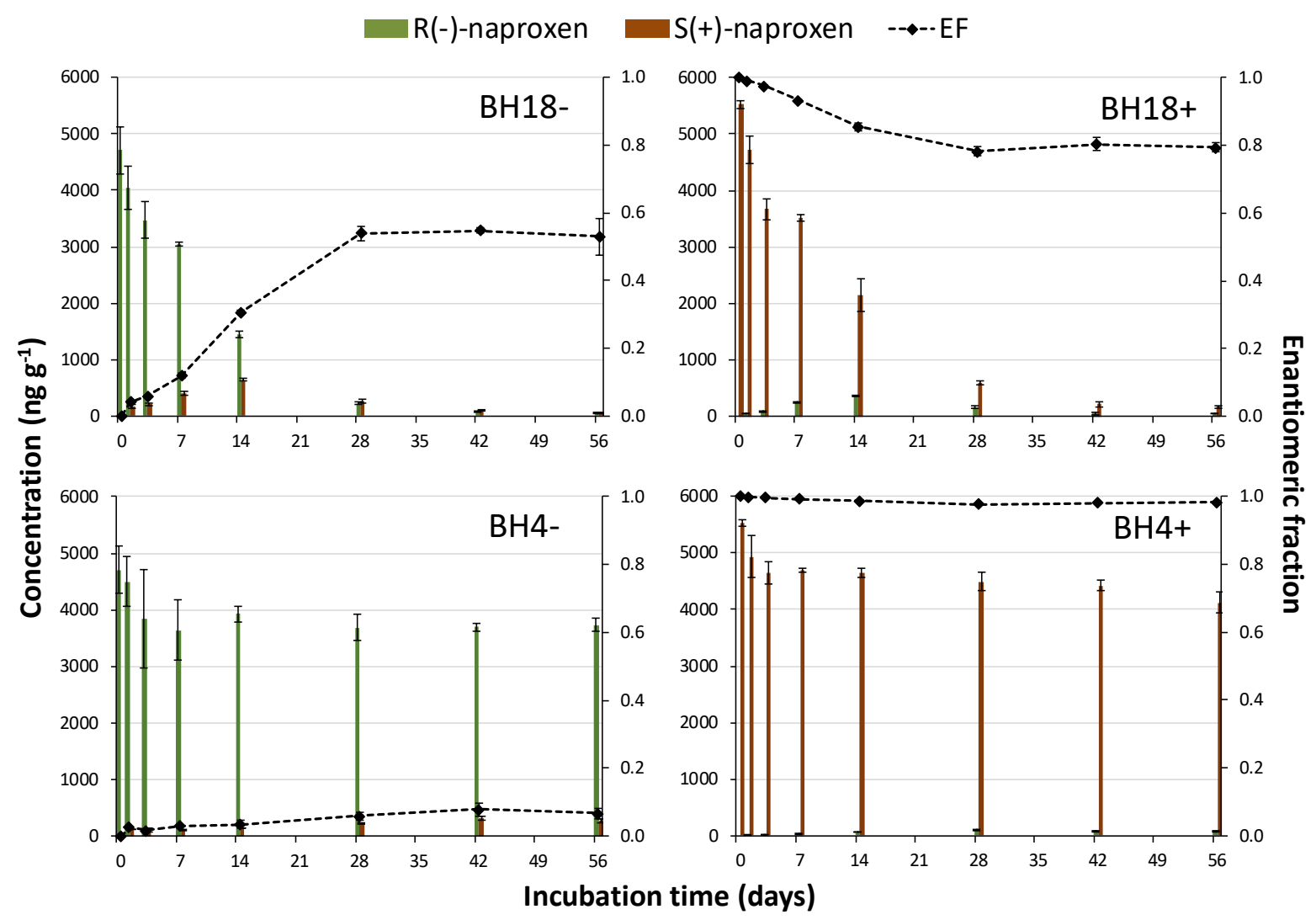

Figure 3. Concentration of $R(-)$-naproxen and $S(+)$-naproxen and the corresponding enantiomeric fraction in soil microcosms spiked with individual naproxen enantiomers

Key: BH18-, biotic high spike level of (-)-enantiomer $18{ }^{\circ} \mathrm{C}$ microcosm; $\mathrm{BH} 18+$, biotic high spike level of (+)-enantiomer $18{ }^{\circ} \mathrm{C}$ microcosm; BH4-, biotic high spike level of (-)-enantiomer $4{ }^{\circ} \mathrm{C}$ microcosm; $\mathrm{BH} 4+$, biotic high spike level of $(+)$-enantiomer $4{ }^{\circ} \mathrm{C}$ microcosm 
Table 1. Degradation rate constants and half-lives of drug enantiomers spiked in racemic microcosms

\begin{tabular}{|c|c|c|c|c|c|}
\hline Drug class & Enantiomer & Microcosm & $k\left(d^{-1}\right)$ & $\mathbf{r}^{2}$ & $t_{1 / 2}(d)$ \\
\hline \multirow[t]{16}{*}{ Anti-inflammatory } & \multirow[t]{4}{*}{$R(-)$-naproxen } & BH18 & $0.071 \pm 0.002$ & 0.987 & $9.7 \pm 0.3$ \\
\hline & & BL18 & $0.101 \pm 0.011$ & 0.890 & $6.9 \pm 0.8$ \\
\hline & & BH4 & $0.011 \pm 0.001$ & 0.779 & $60.6 \pm 4.0$ \\
\hline & & BL4 & $0.024 \pm 0.007$ & 0.780 & $30.5 \pm 9.2$ \\
\hline & \multirow[t]{4}{*}{$S(+)$-naproxen } & BH18 & $0.059 \pm 0.002$ & 0.991 & $11.8 \pm 0.4$ \\
\hline & & BL18 & $0.089 \pm 0.006$ & 0.947 & $7.8 \pm 0.5$ \\
\hline & & BH4 & $0.006 \pm 0.001$ & 0.619 & $109 \pm 12.1$ \\
\hline & & BL4 & $0.012 \pm 0.004$ & 0.638 & $63.8 \pm 22.0$ \\
\hline & \multirow[t]{4}{*}{$R(-)$-ibuprofen } & BH18 & $0.320 \pm 0.050$ & 0.989 & $2.2 \pm 0.4$ \\
\hline & & BL18 & $0.592 \pm 0.268$ & 0.852 & $1.4 \pm 0.9$ \\
\hline & & BH4 & $0.116 \pm 0.011$ & 0.964 & $6.0 \pm 0.6$ \\
\hline & & BL4 & $0.533 \pm 0.141$ & 0.971 & $1.4 \pm 0.4$ \\
\hline & \multirow[t]{4}{*}{$S(+)$-ibuprofen } & BH18 & $0.302 \pm 0.041$ & 0.993 & $2.3 \pm 0.3$ \\
\hline & & BL18 & $0.790 \pm 0.319$ & 0.904 & $1.0 \pm 0.4$ \\
\hline & & BH4 & $0.123 \pm 0.005$ & 0.993 & $5.6 \pm 0.2$ \\
\hline & & BL4 & $0.407 \pm 0.075$ & 0.978 & $1.7 \pm 0.4$ \\
\hline \multirow[t]{8}{*}{ Anti-histamine } & \multirow[t]{4}{*}{$\begin{array}{l}S(+)- \\
\text { chlorpheniramine }\end{array}$} & $\mathrm{BH} 18^{\mathrm{a}}$ & - & - & - \\
\hline & & BL18 ${ }^{\mathrm{a}}$ & - & - & - \\
\hline & & $\mathrm{BH}_{4}^{\mathrm{a}}$ & - & - & - \\
\hline & & $\mathrm{BL}^{\mathrm{a}}$ & - & - & - \\
\hline & \multirow[t]{4}{*}{$R(-)$-chlorpheniramine } & $\mathrm{BH} 18^{\mathrm{a}}$ & - & - & - \\
\hline & & $\mathrm{BL}_{18^{\mathrm{a}}}$ & - & - & - \\
\hline & & $\mathrm{BH}_{4}^{\mathrm{a}}$ & - & - & - \\
\hline & & $\mathrm{BL}^{\mathrm{a}}$ & - & - & - \\
\hline \multirow[t]{28}{*}{ Beta-blocker } & \multirow[t]{4}{*}{ Bisoprolol E1 } & BH18 & $0.034 \pm 0.002$ & 0.969 & $20.4 \pm 1.1$ \\
\hline & & BL18 & $0.093 \pm 0.006$ & 0.948 & $7.5 \pm 0.5$ \\
\hline & & $\mathrm{BH} 4^{\mathrm{a}}$ & - & - & - \\
\hline & & $\mathrm{BL}^{\mathrm{a}}$ & - & - & - \\
\hline & \multirow[t]{4}{*}{ Bisoprolol E2 } & BH18 & $0.036 \pm 0.002$ & 0.969 & $19.4 \pm 1.0$ \\
\hline & & BL18 & $0.083 \pm 0.005$ & 0.968 & $8.4 \pm 0.5$ \\
\hline & & $\mathrm{BH} 4^{\mathrm{a}}$ & - & - & - \\
\hline & & $\mathrm{BL}^{\mathrm{a}}$ & - & - & - \\
\hline & \multirow[t]{4}{*}{ Metoprolol E1 } & BH18 & $0.011 \pm 0.001$ & 0.846 & $63.7 \pm 8.1$ \\
\hline & & BL18 & $0.014 \pm 0.003$ & 0.786 & $49.7 \pm 9.9$ \\
\hline & & $\mathrm{BH} 4^{\mathrm{a}}$ & - & - & - \\
\hline & & $\mathrm{BL}^{\mathrm{a}}$ & - & - & - \\
\hline & \multirow[t]{4}{*}{ Metoprolol E2 } & BH18 & $0.012 \pm 0.002$ & 0.848 & $60.6 \pm 7.9$ \\
\hline & & BL18 & $0.014 \pm 0.002$ & 0.857 & $50.3 \pm 6.8$ \\
\hline & & $\mathrm{BH} 4^{\mathrm{a}}$ & - & - & - \\
\hline & & $\mathrm{BL}^{\mathrm{a}}$ & - & - & - \\
\hline & \multirow[t]{4}{*}{$S(-)$-propranolol } & BH18 & $0.007 \pm 0.001$ & 0.596 & $106 \pm 18.1$ \\
\hline & & BL18 & - & - & - \\
\hline & & $\mathrm{BH}^{\mathrm{b}}$ & - & - & - \\
\hline & & $\mathrm{BL}^{\mathrm{b}}$ & - & - & - \\
\hline & \multirow[t]{4}{*}{$R(+)$-propranolol } & BH18 & $0.008 \pm 0.001$ & 0.619 & $91.4 \pm 11.9$ \\
\hline & & BL18 & - & - & - \\
\hline & & BH4 & $0.006 \pm 0.002$ & 0.600 & $129 \pm 31.4$ \\
\hline & & $\mathrm{BL}^{\mathrm{b}}$ & - & - & - \\
\hline & \multirow[t]{4}{*}{ Acebutolol E1 } & BH18 & $0.019 \pm 0.002$ & 0.919 & $36.9 \pm 3.9$ \\
\hline & & BL18 & $0.021 \pm 0.002$ & 0.817 & $33.4 \pm 3.2$ \\
\hline & & $\mathrm{BH} 4^{\mathrm{a}}$ & - & - & - \\
\hline & & BL4 $^{\mathrm{a}}$ & - & - & - \\
\hline
\end{tabular}




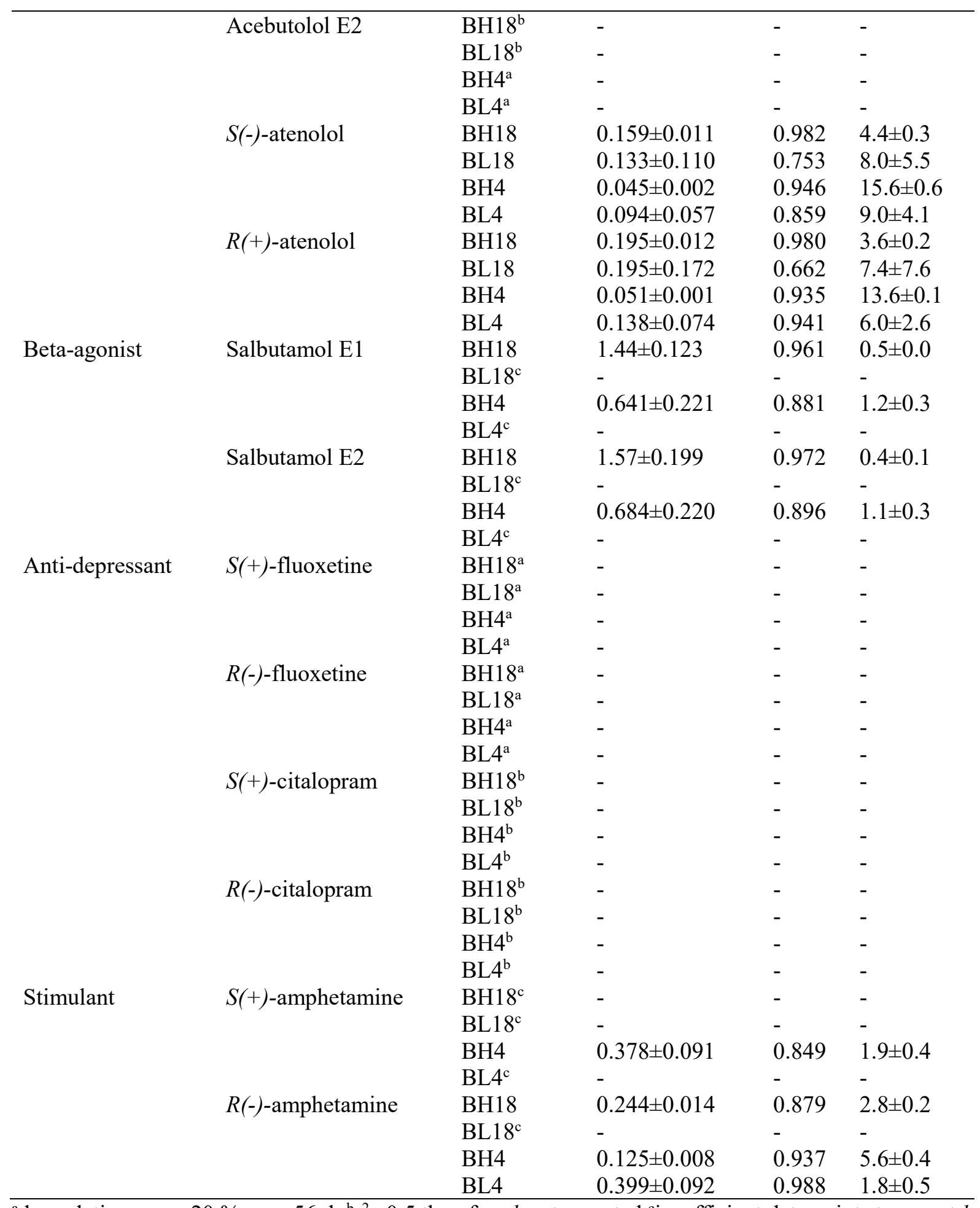

adegradation was $<20 \%$ over $56 \mathrm{~d} ;{ }^{b}{ }^{2}<0.5$ therefore $k$ not reported ${ }^{\text {cinsufficient data points to report } k}$ Key: $k$, degradation rate constant; $t_{1 / 2}$, half-life; $\mathrm{BH} 18$, biotic high spike level $18{ }^{\circ} \mathrm{C}$; BL18, biotic low spike level $18{ }^{\circ} \mathrm{C}$; BH4, biotic high spike level $4{ }^{\circ} \mathrm{C}$; BL4, biotic low spike level $4{ }^{\circ} \mathrm{C}$ 
Supplementary material

\section{Enantiospecific behaviour of chiral drugs in soil}

Sophie Bertin ${ }^{\mathrm{a}}$, Kyari Yates ${ }^{\mathrm{a}}$, Bruce Petrie $\mathrm{a}^{*}$

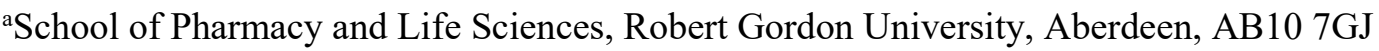

*Corresponding author email: b.r.petrie@rgu.ac.uk Tel. +44 (0)1224 262824

The supplementary material (23 pages) contains 16 figures and four tables. This includes the experimental setup, example chromatograms, comparison of biotic and abiotic soils inoculated on agar plates, degradation of various chiral drugs in soils as racemates and single enantiomers, chemical properties of studied drugs, properties of collected soil, mass spectrometry information and method performance data. 


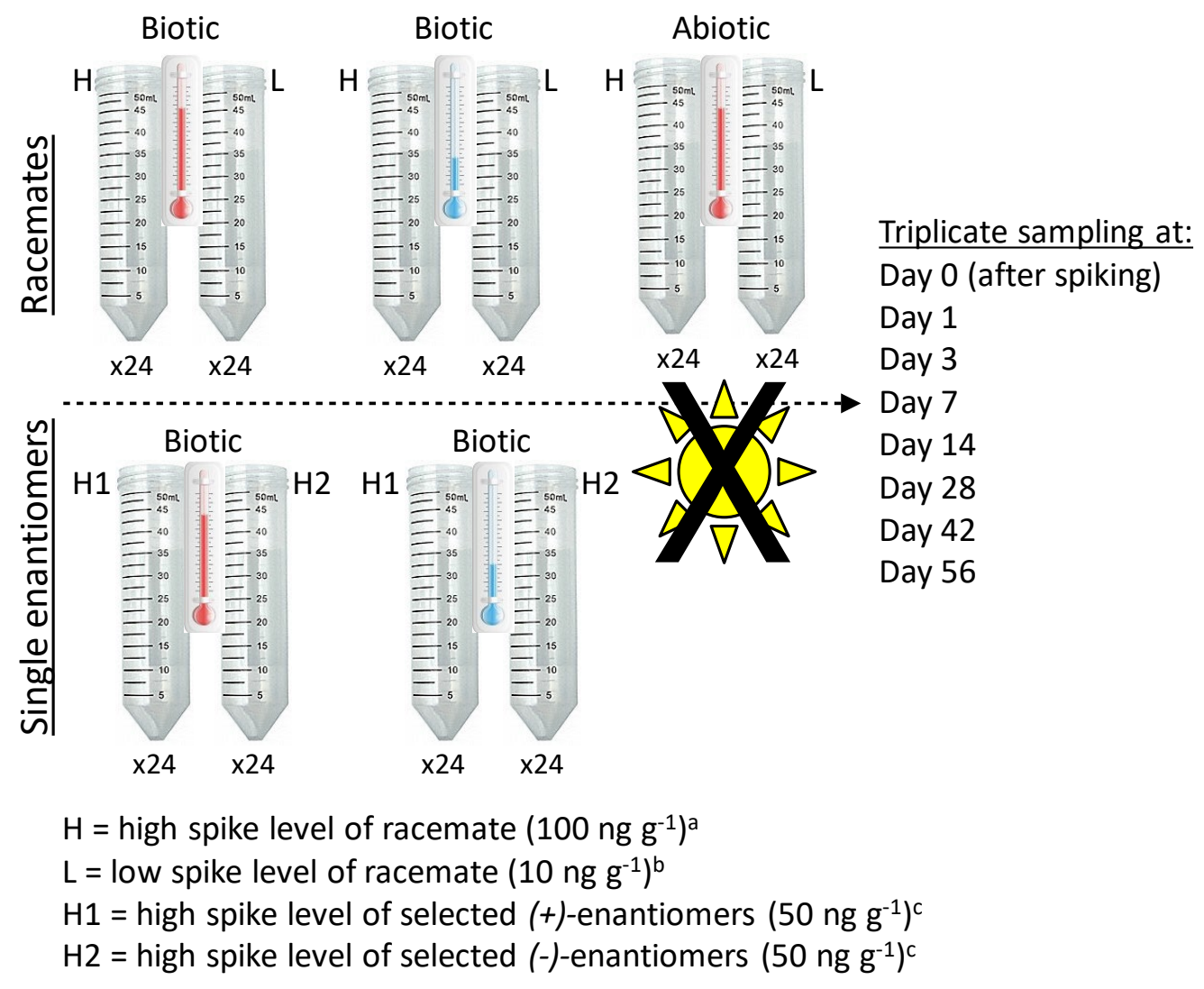

Figure S1. Experimental set-up and incubation conditions for soil microcosms Key: ${ }^{\mathrm{a}} 10,000 \mathrm{ng} \mathrm{g}^{-1}$ for naproxen and ibuprofen ${ }^{\mathrm{b}} 1,000 \mathrm{ng} \mathrm{g}^{-1}$ for naproxen and ibuprofen ${ }^{\mathrm{c}} 5,000 \mathrm{ng} \mathrm{g}^{-1}$ for naproxen and ibuprofen 


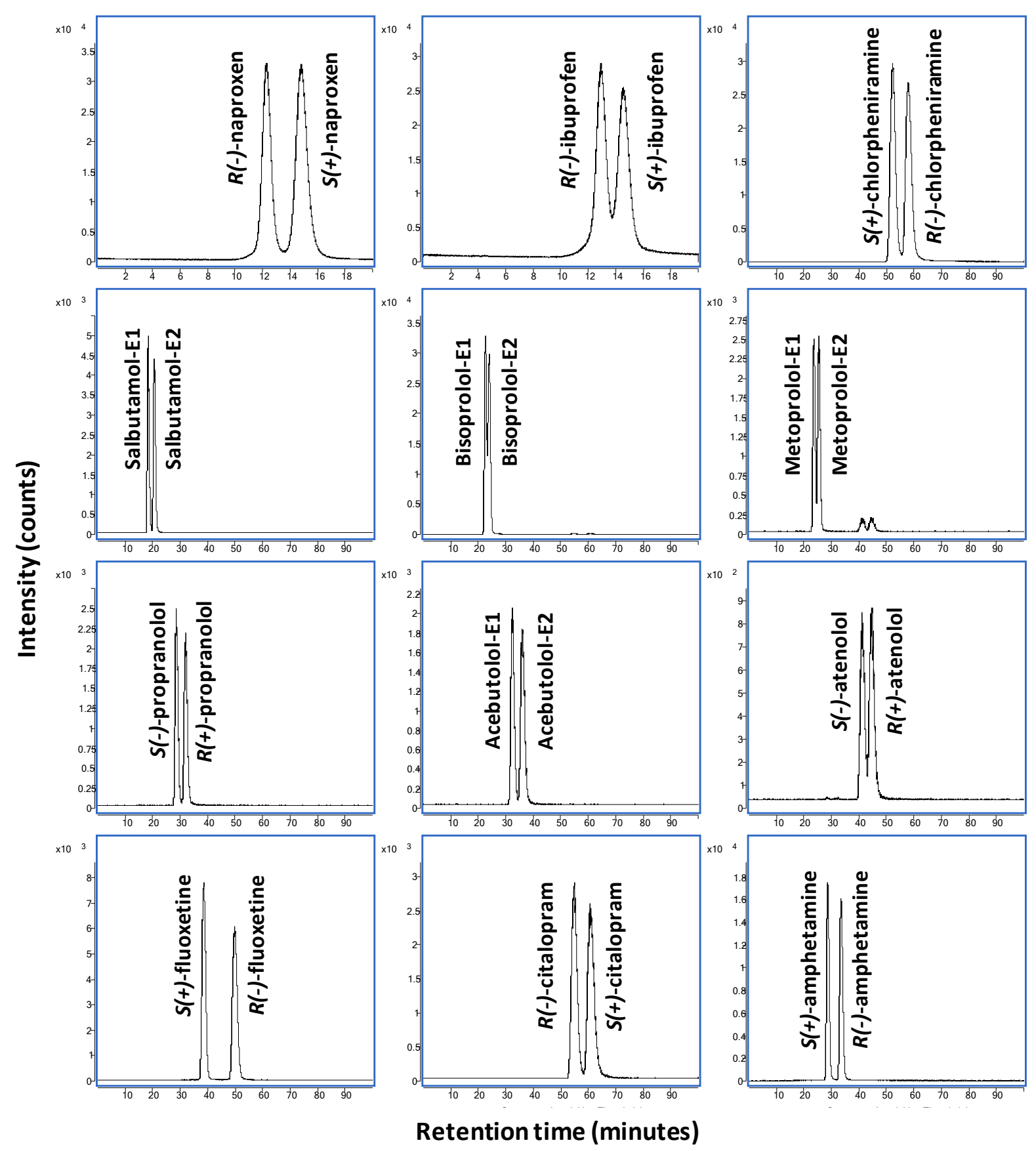

Figure S2. MRM chromatograms of chiral drugs spiked in soil at $100 \mathrm{ng} \mathrm{g}^{-1}\left(10,000 \mathrm{ng} \mathrm{g}^{-1}\right.$ for ibuprofen and naproxen). 


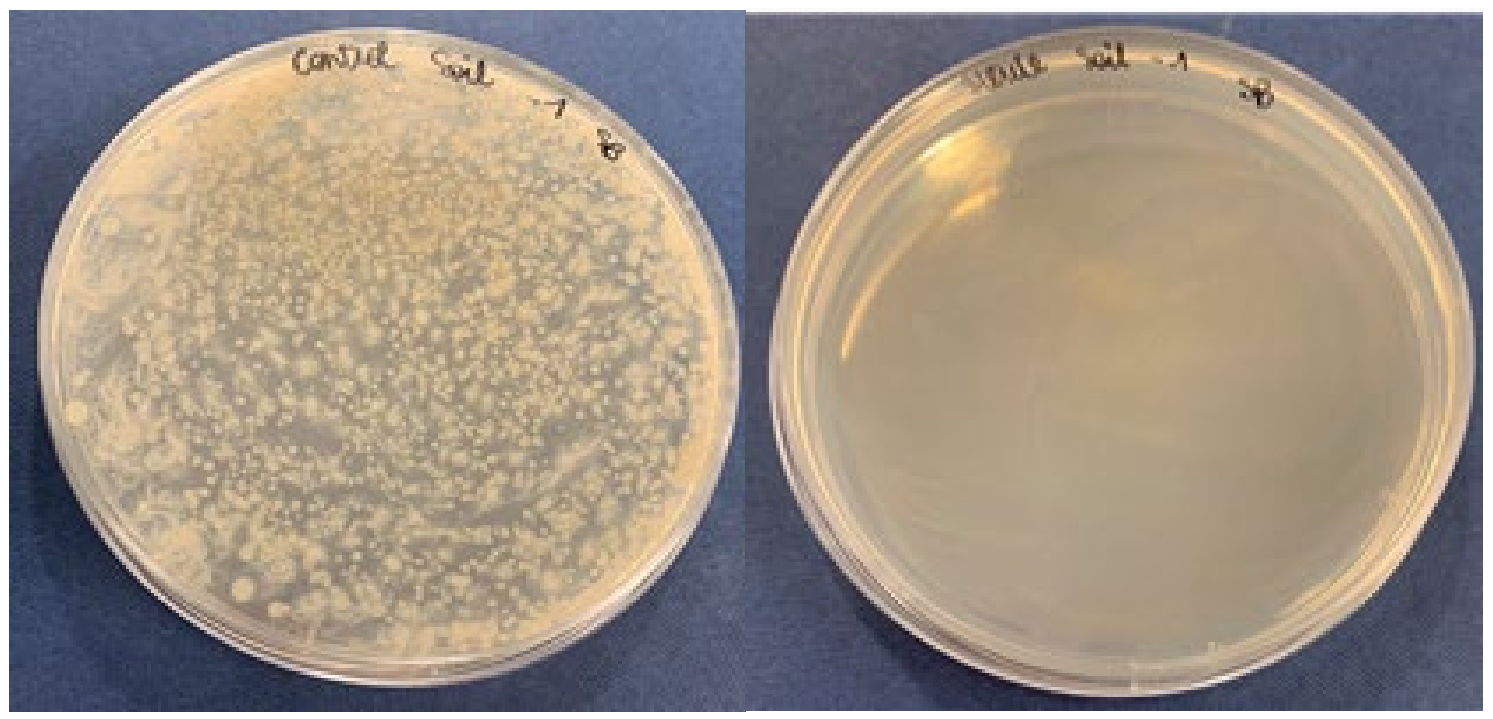

Figure S3. Comparison of $56 \mathrm{~d}$ biotic (left) and abiotic microcosm soil (right) inoculated Petri dishes incubated at $25^{\circ} \mathrm{C}$ for $72 \mathrm{~h}$. 


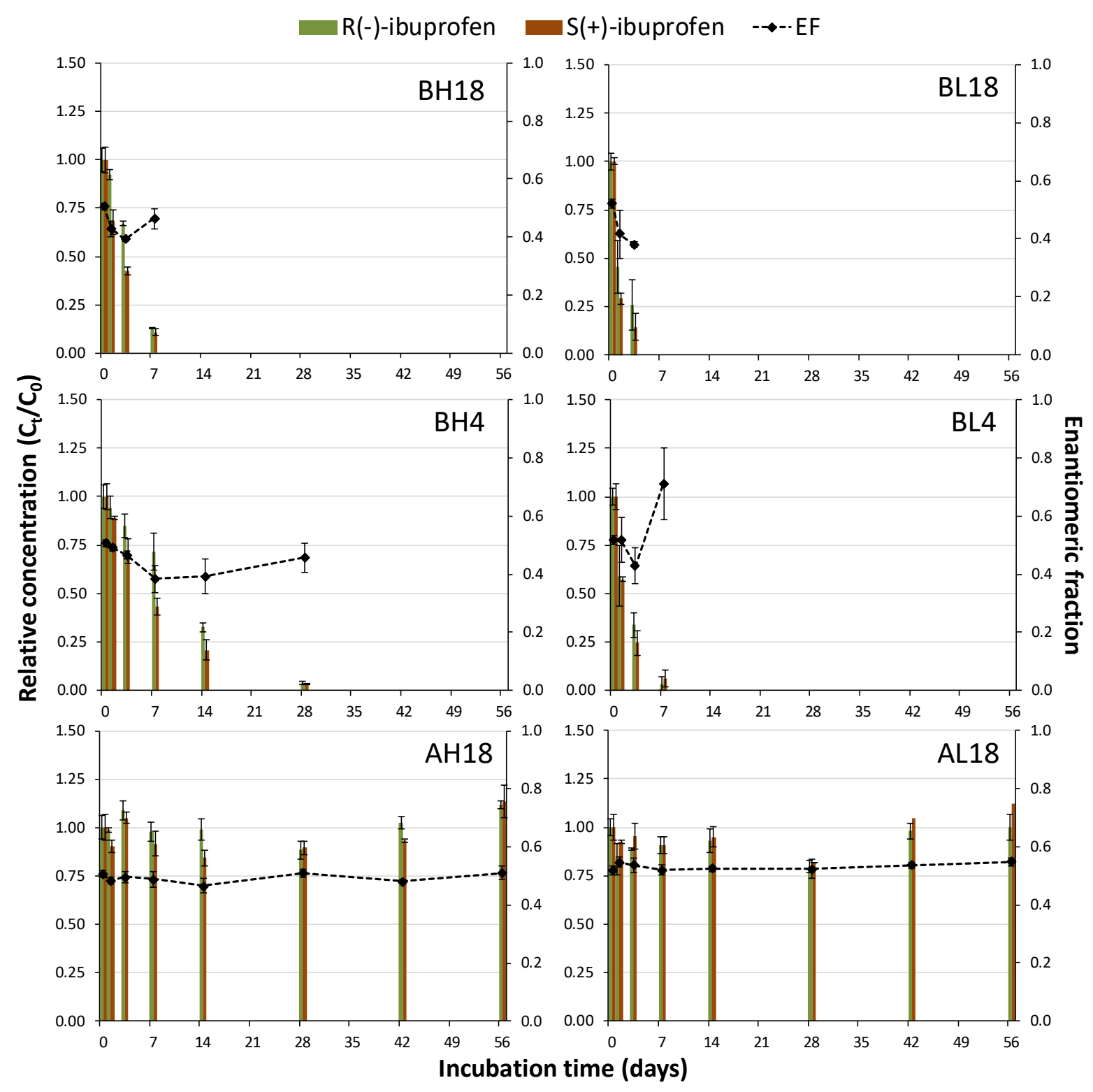

Figure S4. Relative concentration of $R(-)$-ibuprofen and $S(+)$-ibuprofen and the corresponding enantiomeric fraction in soil microcosms spiked with racemic $R / S( \pm)$-ibuprofen

Key: $\mathrm{BH} 18$, biotic high spike level $18{ }^{\circ} \mathrm{C}$ microcosm; BL18, biotic low spike level $18{ }^{\circ} \mathrm{C}$ microcosm; BH4, biotic high spike level $4{ }^{\circ} \mathrm{C}$ microcosm; BL4 biotic low spike level $4{ }^{\circ} \mathrm{C}$ microcosm; AH18, abiotic high spike level $18{ }^{\circ} \mathrm{C}$ microcosm; AL18, abiotic low spike level $18{ }^{\circ} \mathrm{C}$ microcosm. 


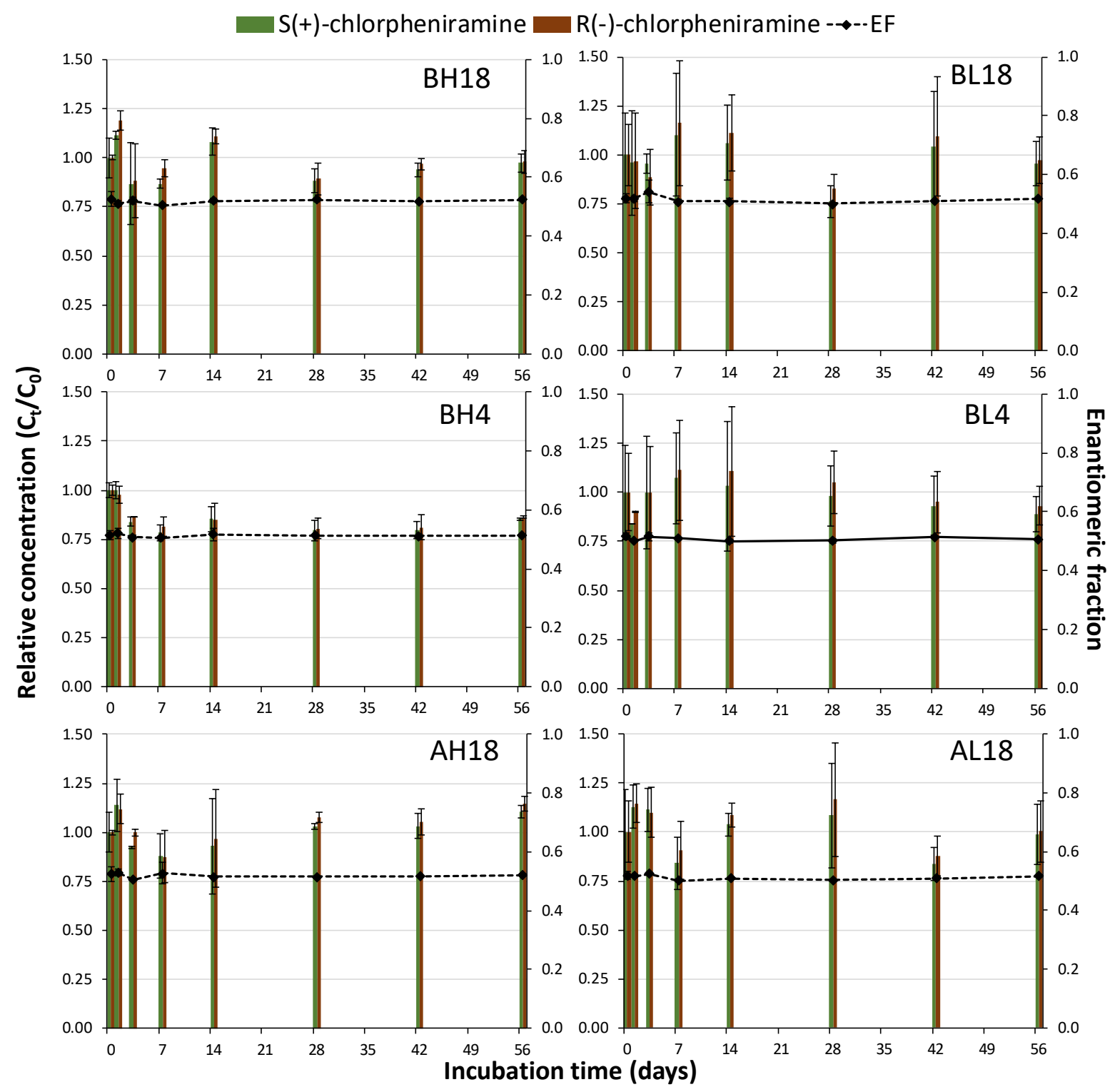

Figure S5. Relative concentration of $S(+)$-chlorpheniramine and $S(-)$-chlorpheniramine and the corresponding enantiomeric fraction in soil microcosms spiked with racemic $R / S( \pm)$-chlorpheniramine

Key: BH18, biotic high spike level $18{ }^{\circ} \mathrm{C}$ microcosm; BL18, biotic low spike level $18{ }^{\circ} \mathrm{C}$ microcosm; BH4, biotic high spike level $4{ }^{\circ} \mathrm{C}$ microcosm; BL4 biotic low spike level $4{ }^{\circ} \mathrm{C}$ microcosm; AH18, abiotic high spike level $18{ }^{\circ} \mathrm{C}$ microcosm; AL18, abiotic low spike level $18{ }^{\circ} \mathrm{C}$ microcosm. 


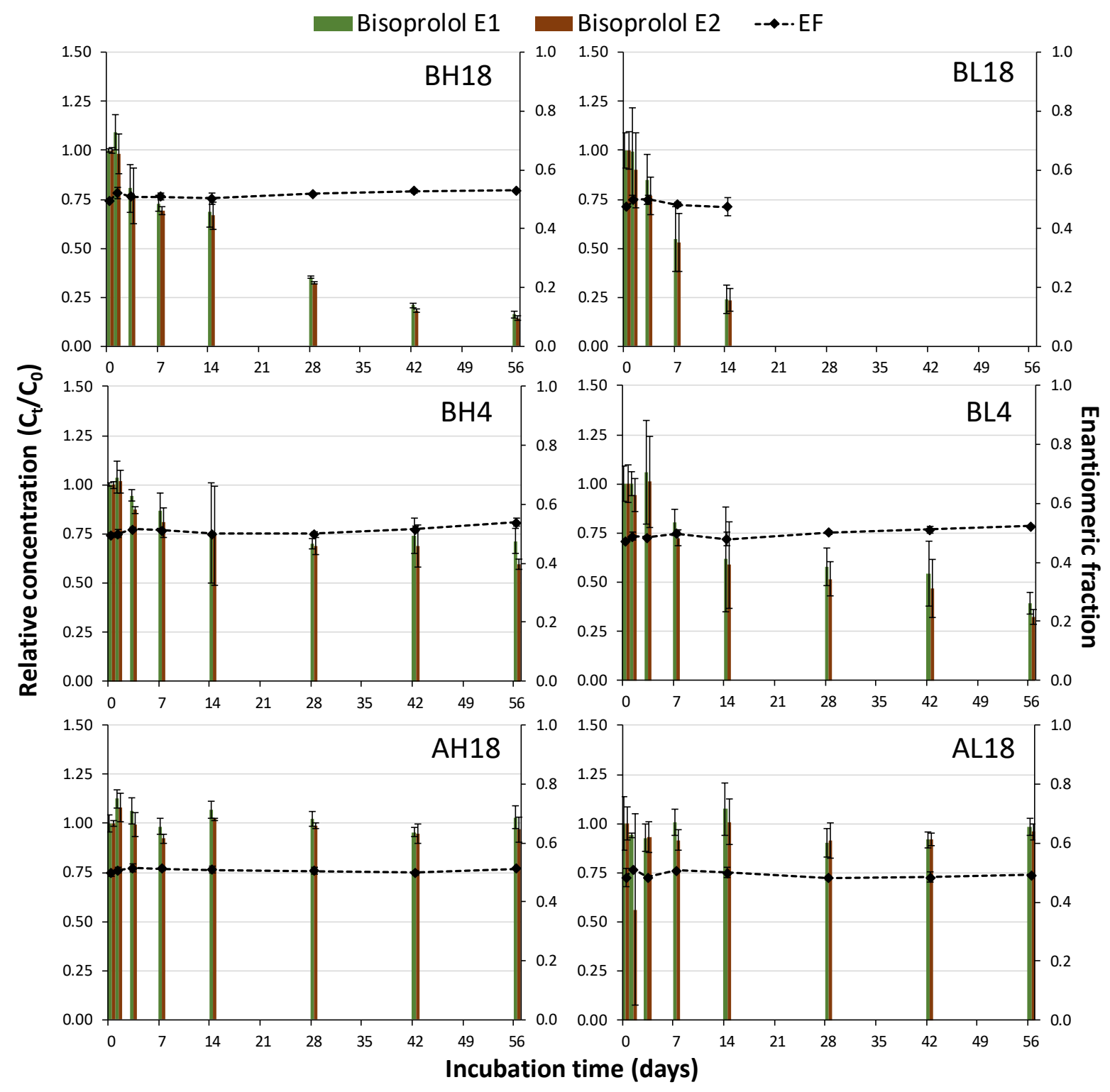

Figure S6. Relative concentration of bisoprolol E1 and bisoprolol E2 and the corresponding enantiomeric fraction in soil microcosms spiked with racemic $R / S( \pm)$-bisoprolol

Key: $\mathrm{BH} 18$, biotic high spike level $18{ }^{\circ} \mathrm{C}$ microcosm; BL18, biotic low spike level $18{ }^{\circ} \mathrm{C}$ microcosm; BH4, biotic high spike level $4{ }^{\circ} \mathrm{C}$ microcosm; BL4 biotic low spike level $4{ }^{\circ} \mathrm{C}$ microcosm; AH18, abiotic high spike level $18{ }^{\circ} \mathrm{C}$ microcosm; AL18, abiotic low spike level $18{ }^{\circ} \mathrm{C}$ microcosm. 


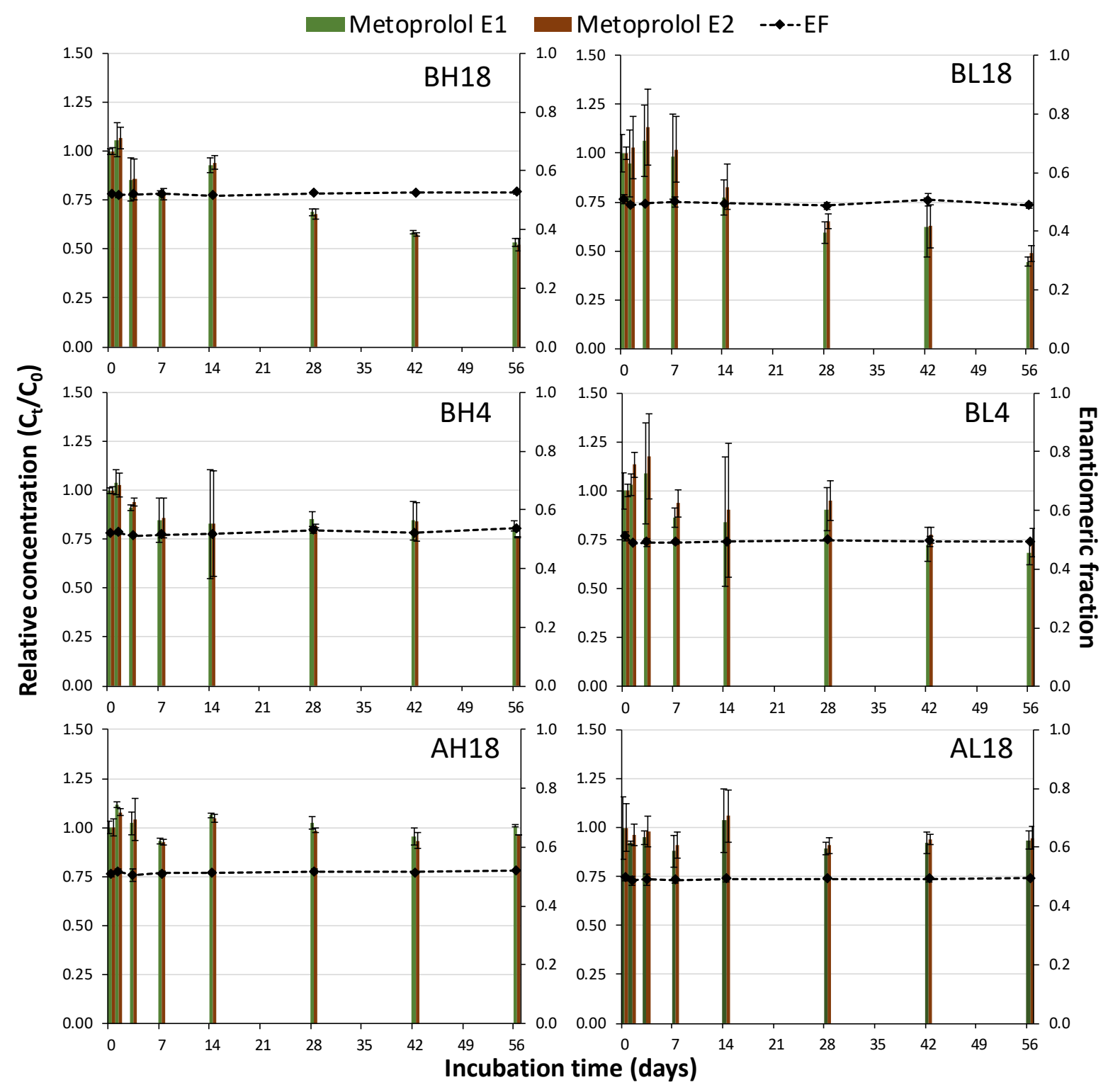

Figure S7. Relative concentration of metoprolol E1 and metoprolol E2 and the corresponding enantiomeric fraction in soil microcosms spiked with racemic $R / S( \pm)$-metoprolol

Key: $\mathrm{BH} 18$, biotic high spike level $18{ }^{\circ} \mathrm{C}$ microcosm; BL18, biotic low spike level $18{ }^{\circ} \mathrm{C}$ microcosm; BH4, biotic high spike level $4{ }^{\circ} \mathrm{C}$ microcosm; BL4 biotic low spike level $4{ }^{\circ} \mathrm{C}$ microcosm; AH18, abiotic high spike level $18{ }^{\circ} \mathrm{C}$ microcosm; AL18, abiotic low spike level $18{ }^{\circ} \mathrm{C}$ microcosm. 


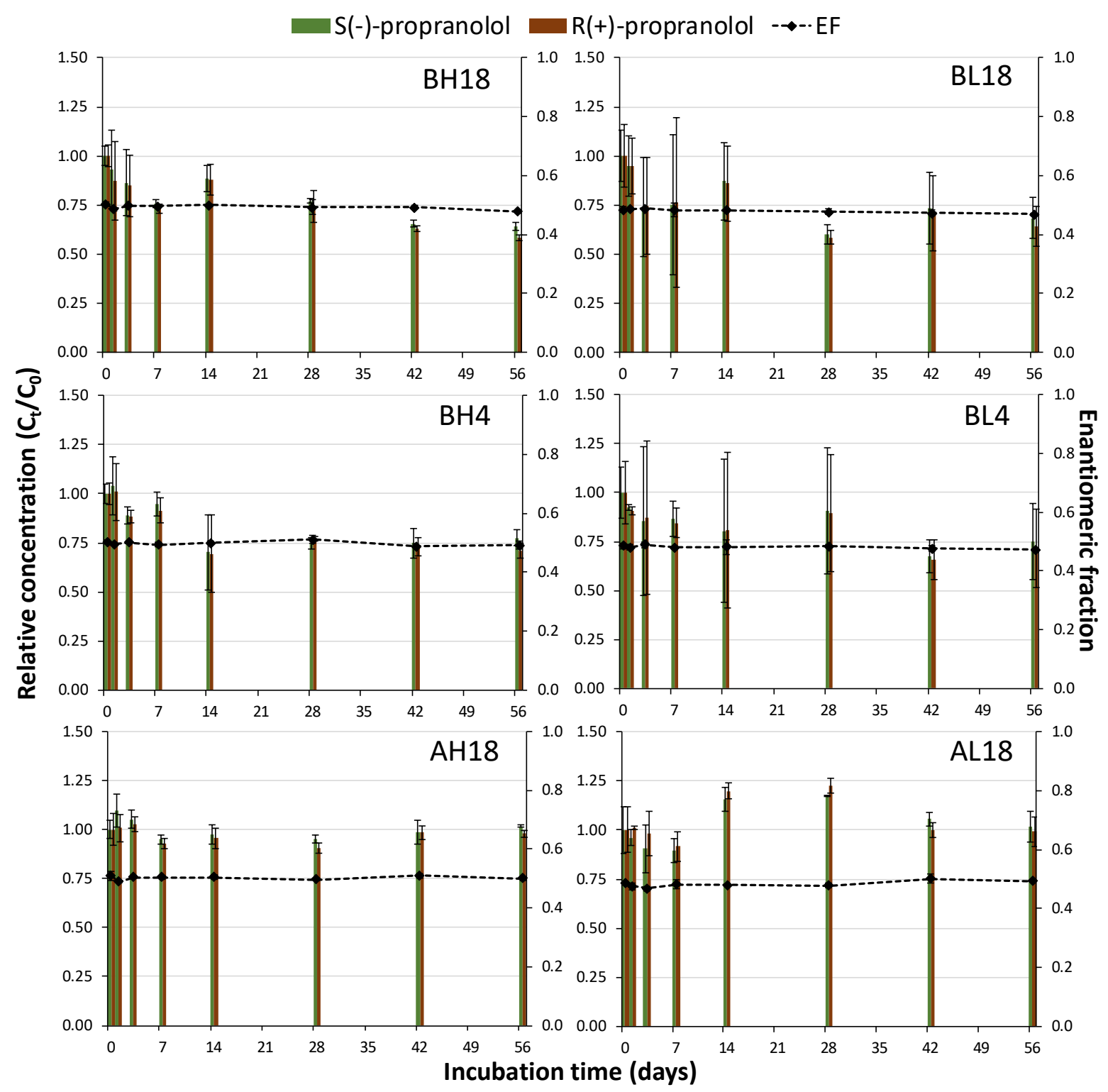

Figure S8. Relative concentration of $S(-)$-propranolol $R(+)$-propranolol and the corresponding enantiomeric fraction in soil microcosms spiked with racemic $R / S( \pm)$-propranolol

Key: BH18, biotic high spike level $18{ }^{\circ} \mathrm{C}$ microcosm; BL18, biotic low spike level $18{ }^{\circ} \mathrm{C}$ microcosm; BH4, biotic high spike level $4{ }^{\circ} \mathrm{C}$ microcosm; BL4 biotic low spike level $4{ }^{\circ} \mathrm{C}$ microcosm; AH18, abiotic high spike level $18{ }^{\circ} \mathrm{C}$ microcosm; AL18, abiotic low spike level $18{ }^{\circ} \mathrm{C}$ microcosm. 


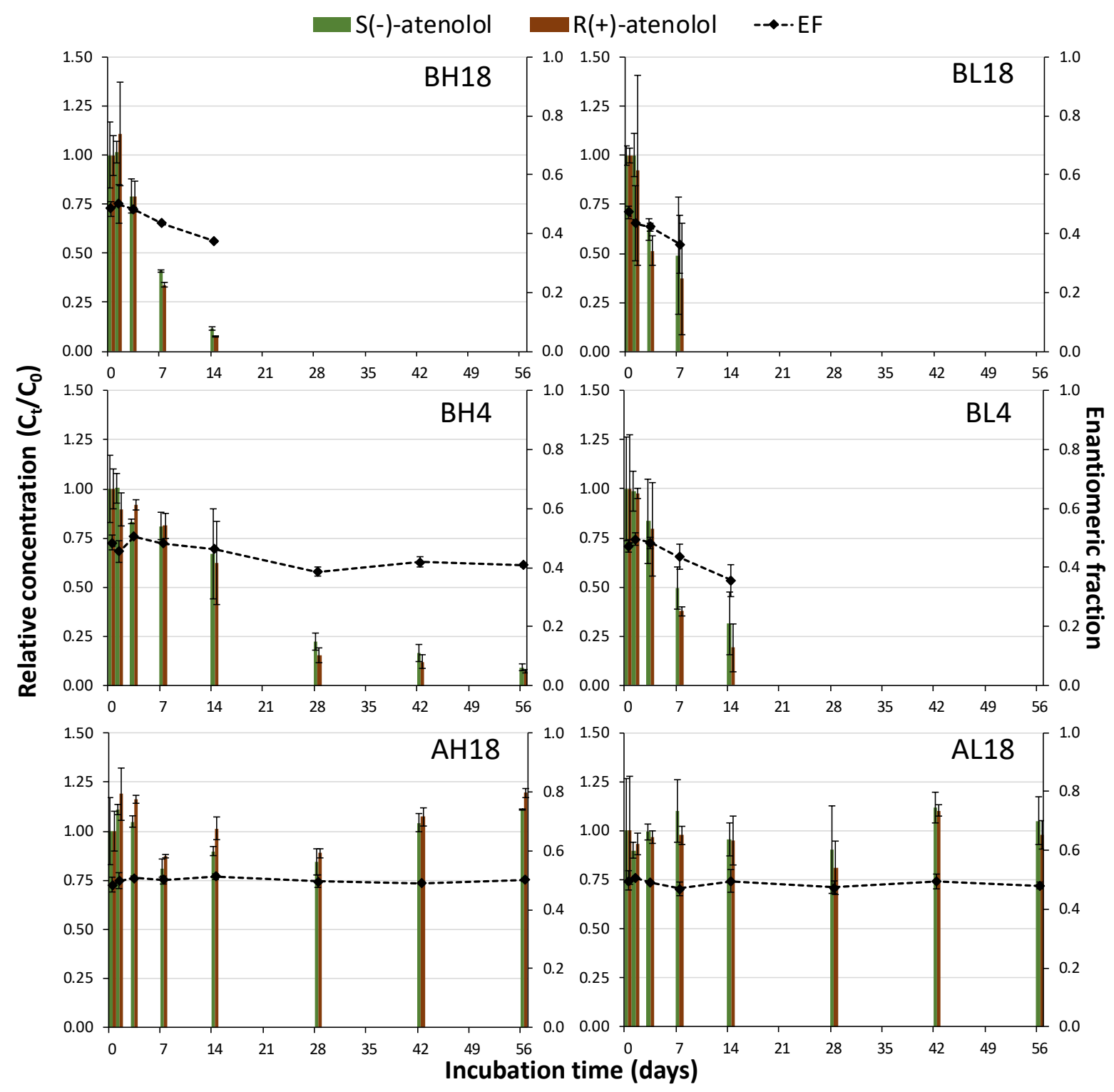

Figure S9. Relative concentration of $S(-)$-atenolol and $R(+)$-atenolol and the corresponding enantiomeric fraction in soil microcosms spiked with racemic $R / S( \pm)$-atenolol

Key: BH18, biotic high spike level $18{ }^{\circ} \mathrm{C}$ microcosm; BL18, biotic low spike level $18{ }^{\circ} \mathrm{C}$ microcosm; BH4, biotic high spike level $4{ }^{\circ} \mathrm{C}$ microcosm; BL4 biotic low spike level $4{ }^{\circ} \mathrm{C}$ microcosm; AH18, abiotic high spike level $18{ }^{\circ} \mathrm{C}$ microcosm; AL18, abiotic low spike level $18{ }^{\circ} \mathrm{C}$ microcosm. 


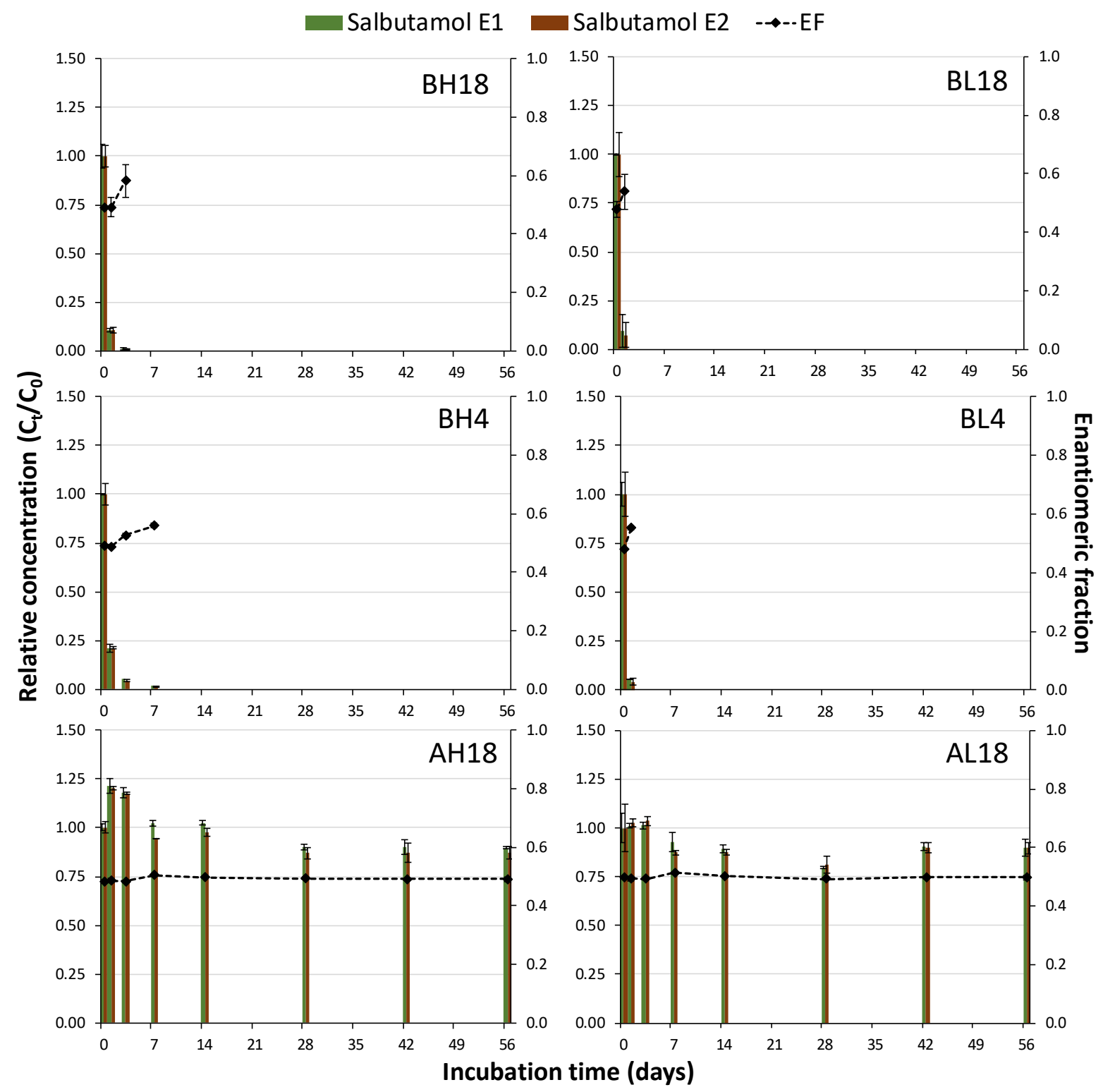

Figure S10. Relative concentration of salbutamol E1 and salbutamol E2 and the corresponding enantiomeric fraction in soil microcosms spiked with racemic $R / S( \pm)$-salbutamol

Key: BH18, biotic high spike level $18{ }^{\circ} \mathrm{C}$ microcosm; BL18, biotic low spike level $18{ }^{\circ} \mathrm{C}$ microcosm; $\mathrm{BH} 4$, biotic high spike level $4{ }^{\circ} \mathrm{C}$ microcosm; BL4 biotic low spike level $4{ }^{\circ} \mathrm{C}$ microcosm; AH18, abiotic high spike level $18{ }^{\circ} \mathrm{C}$ microcosm; AL18, abiotic low spike level $18{ }^{\circ} \mathrm{C}$ microcosm. 


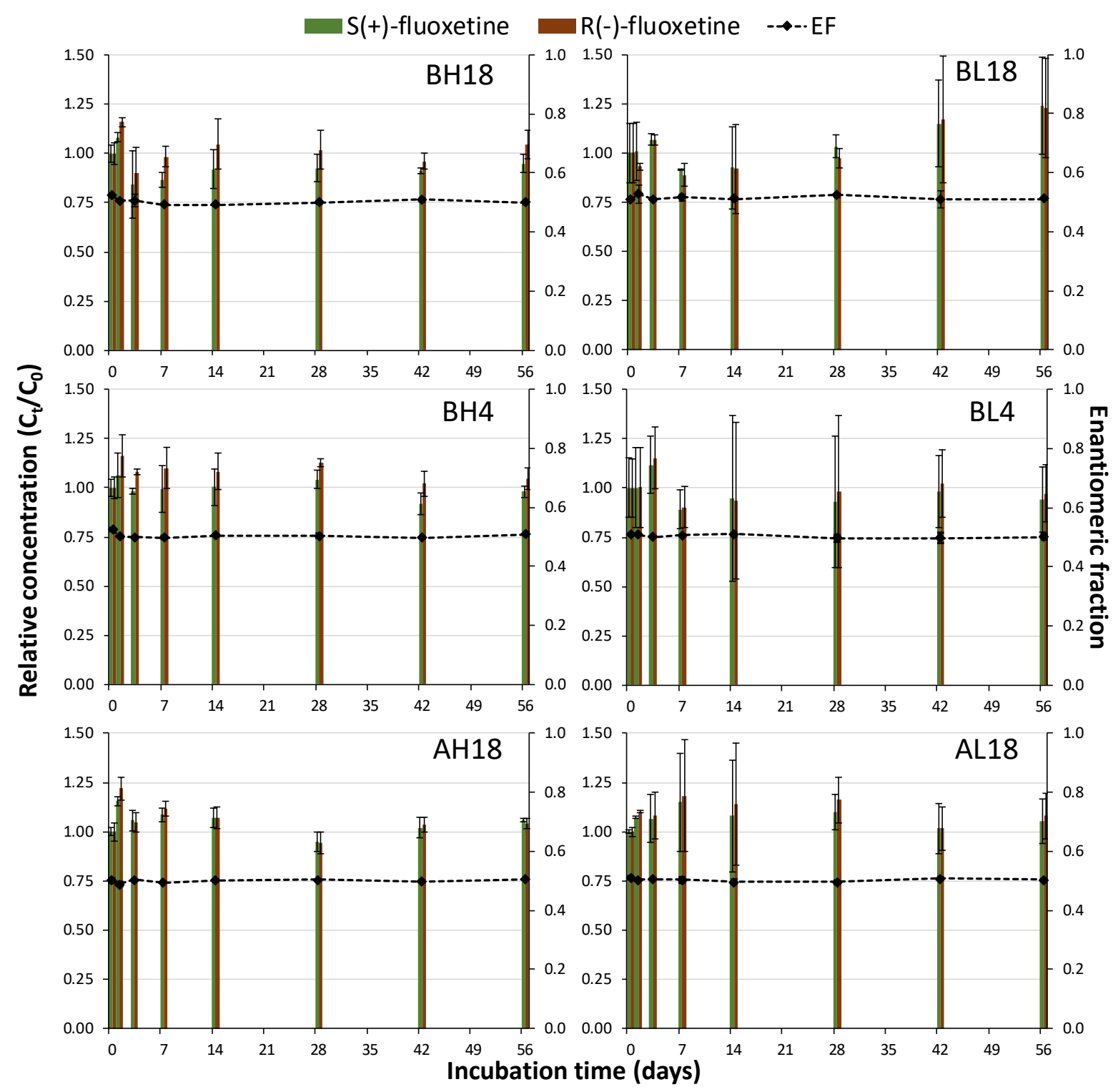

Figure S11. Relative concentration of $S(+)$-fluoxetine and $R(-)$-fluoxetine and the corresponding enantiomeric fraction in soil microcosms spiked with racemic $R / S( \pm)$-fluoxetine

Key: BH18, biotic high spike level $18{ }^{\circ} \mathrm{C}$ microcosm; BL18, biotic low spike level $18{ }^{\circ} \mathrm{C}$ microcosm; BH4, biotic high spike level $4{ }^{\circ} \mathrm{C}$ microcosm; BL4 biotic low spike level $4{ }^{\circ} \mathrm{C}$ microcosm; AH18, abiotic high spike level $18{ }^{\circ} \mathrm{C}$ microcosm; AL18, abiotic low spike level $18{ }^{\circ} \mathrm{C}$ microcosm. 


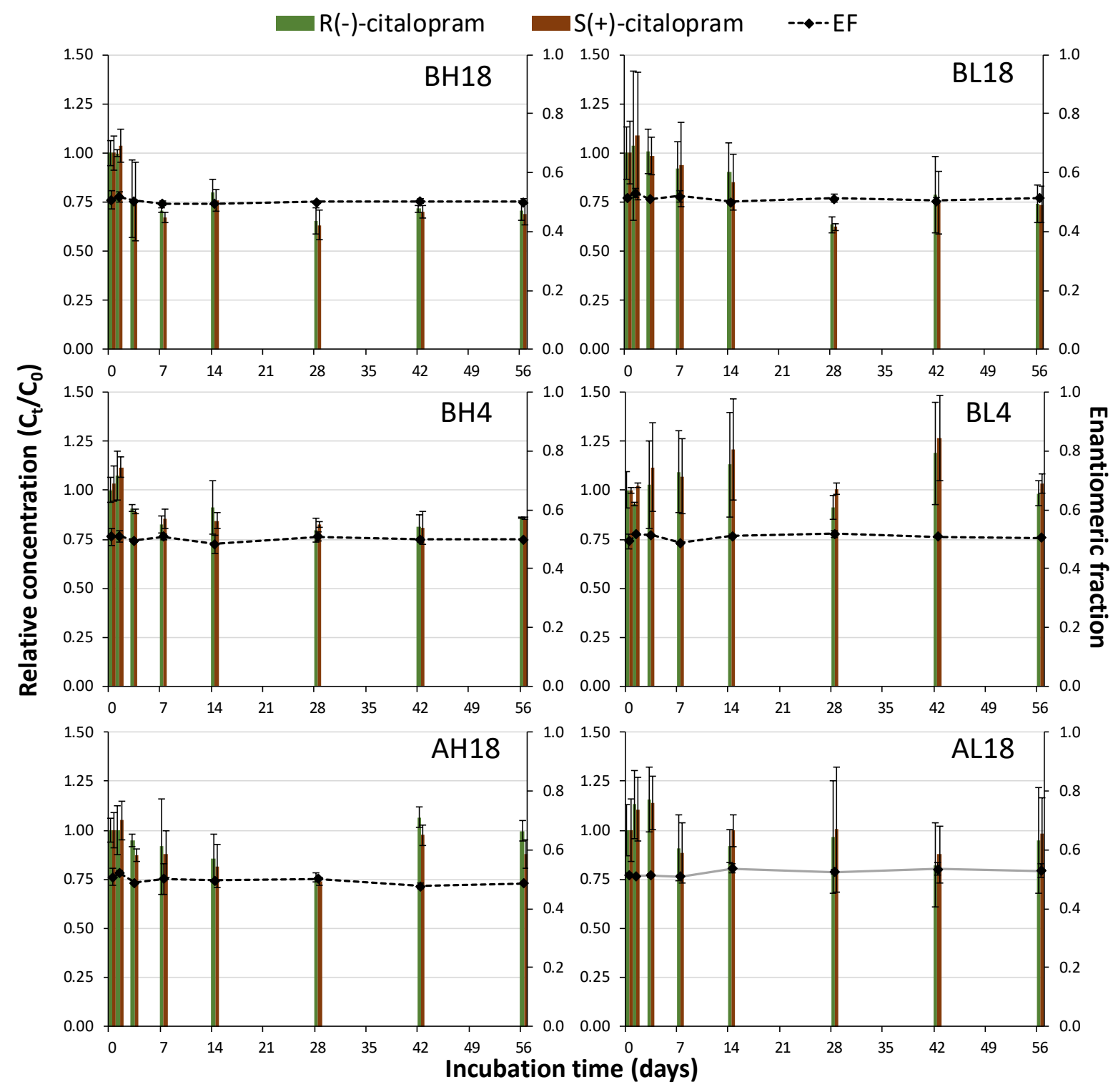

Figure S12. Relative concentration of $R(-)$-citalopram and $S(+)$-citalopram and the corresponding enantiomeric fraction in soil microcosms spiked with racemic $R / S( \pm)$-citalopram

Key: BH18, biotic high spike level $18{ }^{\circ} \mathrm{C}$ microcosm; BL18, biotic low spike level $18{ }^{\circ} \mathrm{C}$ microcosm; BH4, biotic high spike level $4{ }^{\circ} \mathrm{C}$ microcosm; BL4 biotic low spike level $4{ }^{\circ} \mathrm{C}$ microcosm; AH18, abiotic high spike level $18{ }^{\circ} \mathrm{C}$ microcosm; AL18, abiotic low spike level $18{ }^{\circ} \mathrm{C}$ microcosm. 


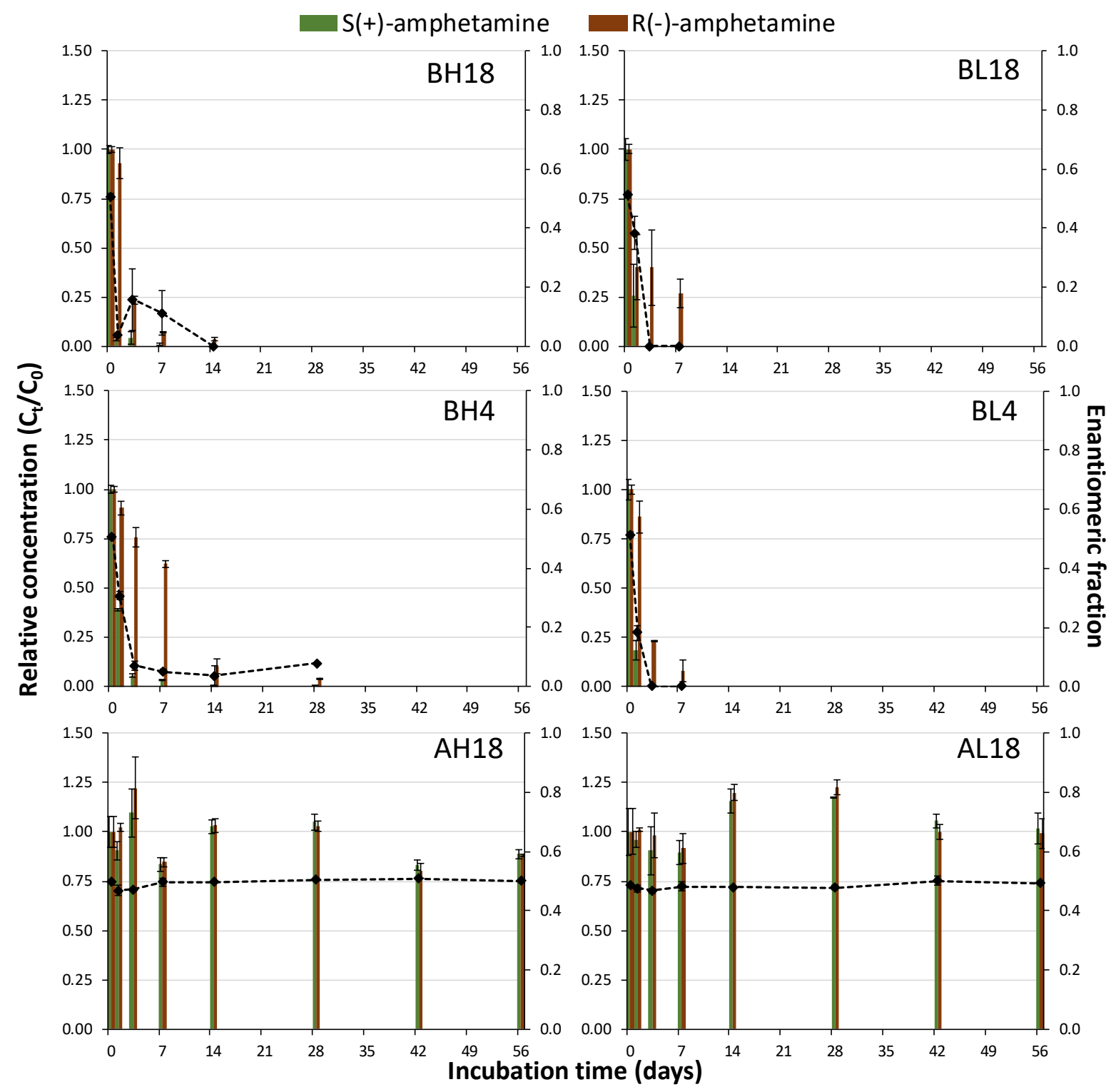

Figure S13. Relative concentration of $S(+)$-amphetamine $R(-)$-amphetamine and the corresponding enantiomeric fraction in soil microcosms spiked with racemic $R / S( \pm)$-amphetamine

Key: BH18, biotic high spike level $18{ }^{\circ} \mathrm{C}$ microcosm; BL18, biotic low spike level $18{ }^{\circ} \mathrm{C}$ microcosm; BH4, biotic high spike level $4{ }^{\circ} \mathrm{C}$ microcosm; BL4 biotic low spike level $4{ }^{\circ} \mathrm{C}$ microcosm; AH18, abiotic high spike level $18{ }^{\circ} \mathrm{C}$ microcosm; AL18, abiotic low spike level $18{ }^{\circ} \mathrm{C}$ microcosm. 


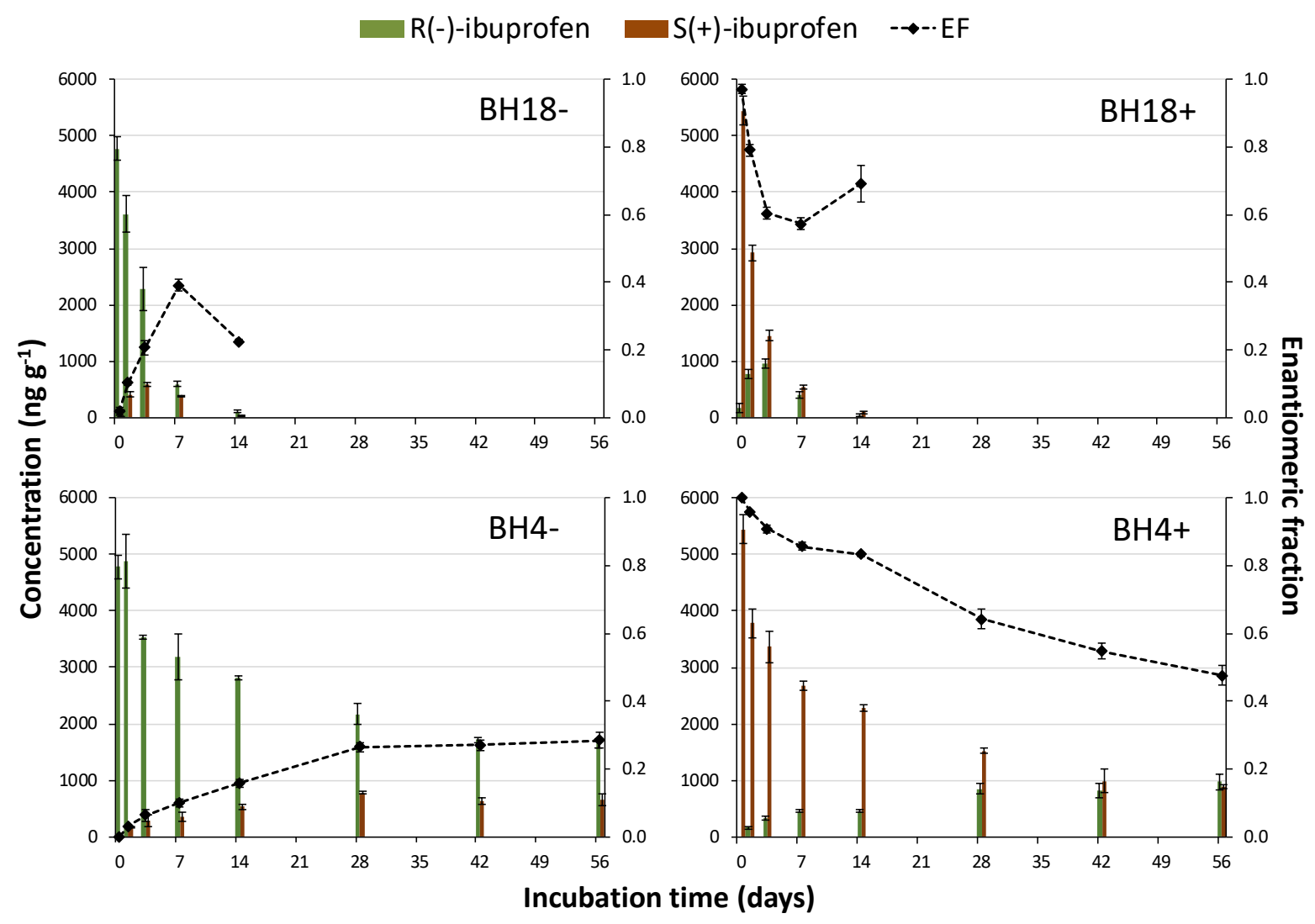

Figure S14. Concentration of $R(-)$-ibuprofen and $S(+)$-ibuprofen and the corresponding enantiomeric fraction in soil microcosms spiked with individual ibuprofen enantiomers

Key: BH18-, biotic high spike level of (-)-enantiomer $18{ }^{\circ} \mathrm{C}$ microcosm; $\mathrm{BH} 18+$, biotic high spike level of (+)-enantiomer $18{ }^{\circ} \mathrm{C}$ microcosm; BH4-, biotic high spike level of (-)-enantiomer $4{ }^{\circ} \mathrm{C}$ microcosm; $\mathrm{BH} 4+$, biotic high spike level of (+)-enantiomer $4{ }^{\circ} \mathrm{C}$ microcosm 


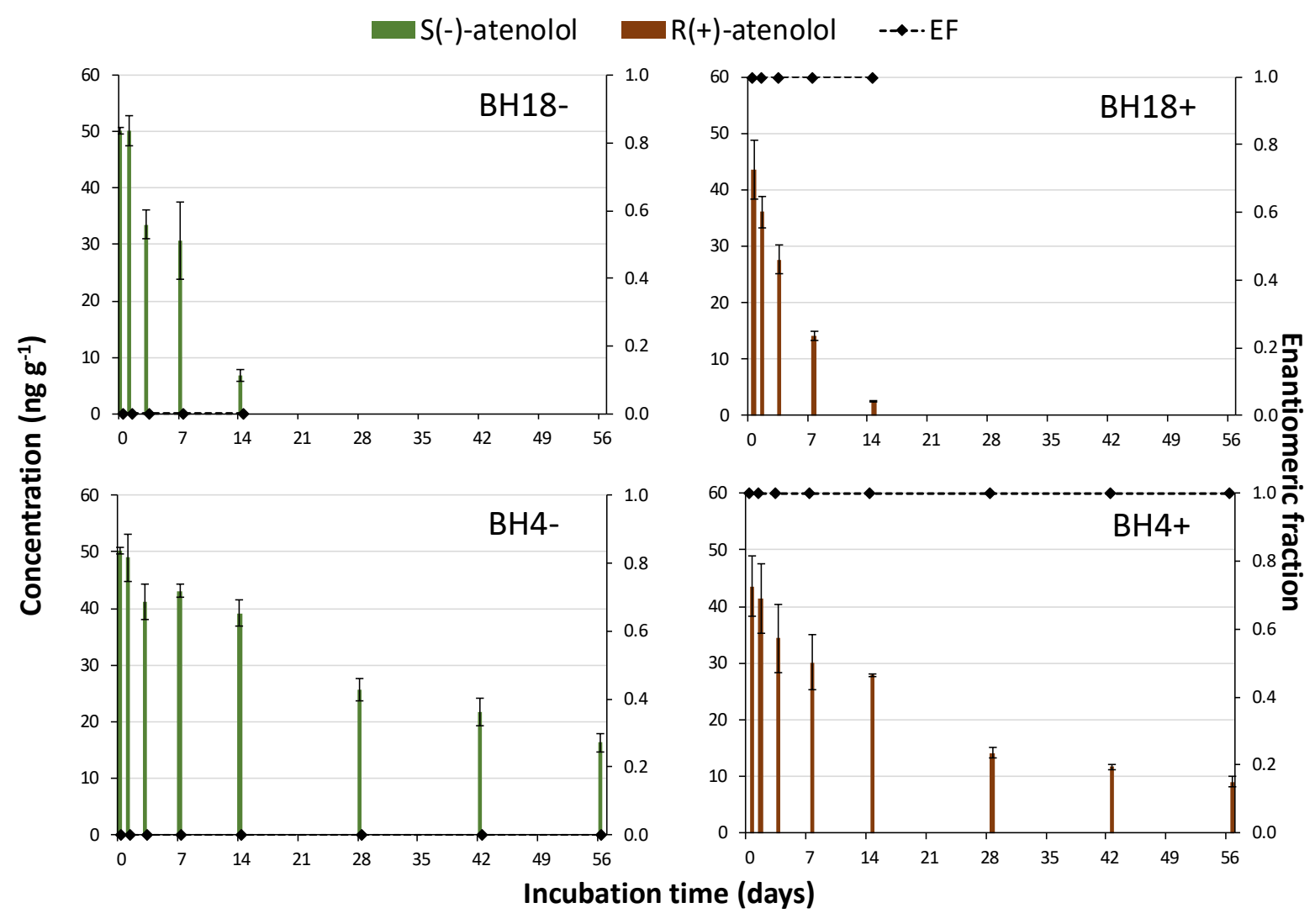

Figure S15. Concentration of $S(-)$-atenolol and $R(+)$-atenolol and the corresponding enantiomeric fraction in soil microcosms spiked with individual atenolol enantiomers

Key: BH18-, biotic high spike level of (-)-enantiomer $18{ }^{\circ} \mathrm{C}$ microcosm; $\mathrm{BH} 18+$, biotic high spike level of (+)-enantiomer $18{ }^{\circ} \mathrm{C}$ microcosm; $\mathrm{BH} 4$-, biotic high spike level of (-)-enantiomer $4{ }^{\circ} \mathrm{C}$ microcosm; $\mathrm{BH} 4+$, biotic high spike level of $(+)$-enantiomer $4{ }^{\circ} \mathrm{C}$ microcosm 


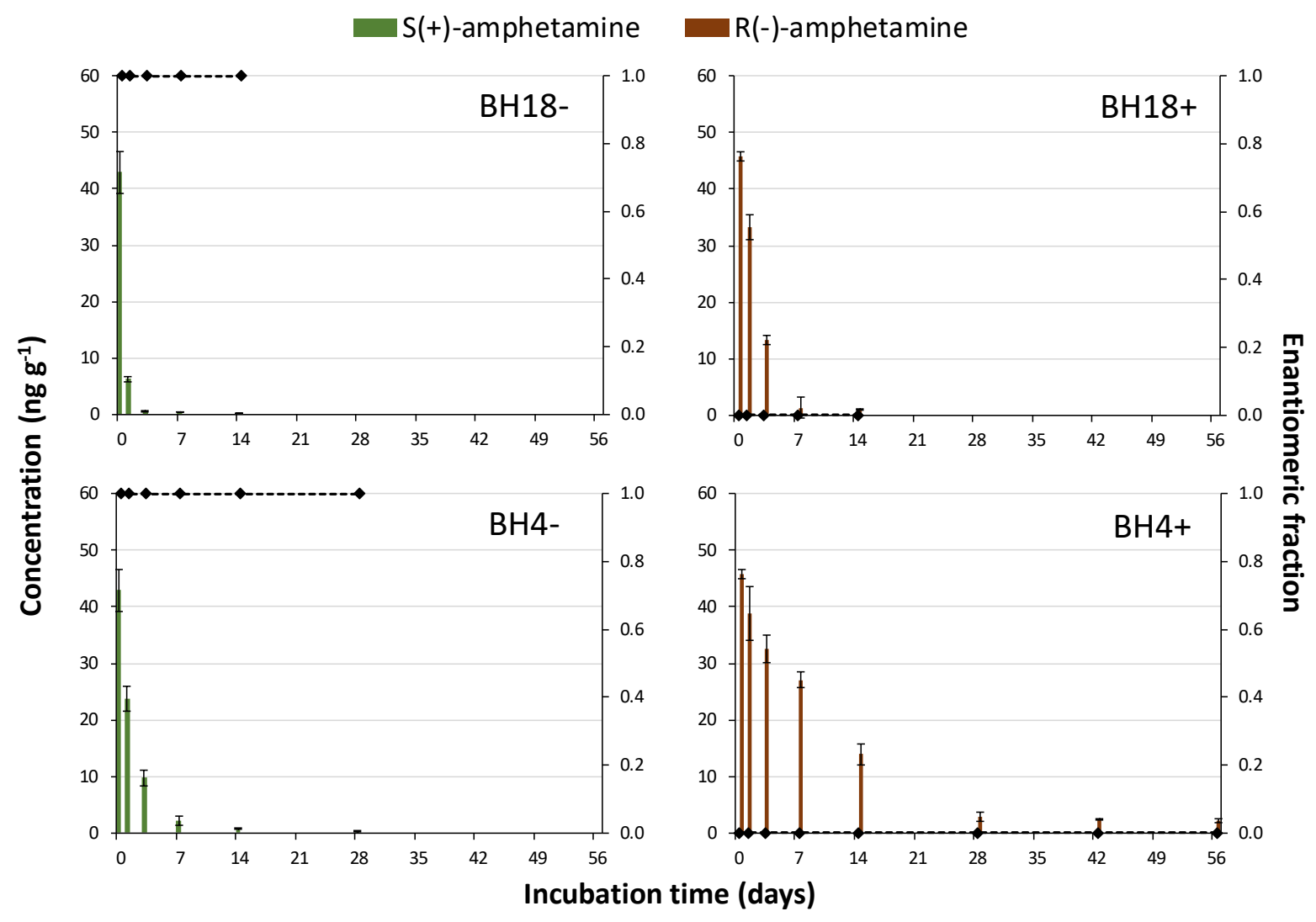

Figure S16. Concentration of $S(+)$-amphetamine and $R(-)$-amphetamine and the corresponding enantiomeric fraction in soil microcosms spiked with individual amphetamine enantiomers

Key: BH18-, biotic high spike level of (-)-enantiomer $18{ }^{\circ} \mathrm{C}$ microcosm; $\mathrm{BH} 18+$, biotic high spike level of (+)-enantiomer $18{ }^{\circ} \mathrm{C}$ microcosm; $\mathrm{BH} 4$-, biotic high spike level of (-)-enantiomer $4{ }^{\circ} \mathrm{C}$ microcosm; $\mathrm{BH} 4+$, biotic high spike level of $(+)$-enantiomer $4{ }^{\circ} \mathrm{C}$ microcosm 
Table S1. Chemical properties of studied chiral drugs (US EPA, 2015)

\begin{tabular}{|c|c|c|c|c|c|}
\hline Drug & Chemical structure & $\begin{array}{c}\text { Molecular weight } \\
\qquad\left(\mathrm{g} \mathrm{mol}^{-1}\right)\end{array}$ & $\begin{array}{c}\text { Water solubility } \\
\left(\mathrm{mg} \mathrm{L}^{-1}\right)\end{array}$ & Log Kow & $\mathrm{p} K a$ \\
\hline Naproxen & & 230.26 & 15.9 & 3.18 & 4.15 \\
\hline Ibuprofen & & 206.28 & 21.0 & 3.97 & 4.91 \\
\hline Chlorpheniramine & & 274.79 & $5.5 \mathrm{E} 3$ & 3.67 & 9.47 (basic) \\
\hline Salbutamol & & 239.31 & $1.4 \mathrm{E} 4$ & 0.40 & $\begin{array}{l}10.12 \text { (acidic) } \\
9.40 \text { (basic) }\end{array}$ \\
\hline Bisoprolol & & 325.44 & $2.2 \mathrm{E} 3$ & 1.87 & $\begin{array}{l}14.09 \text { (acidic) } \\
9.27 \text { (basic) }\end{array}$ \\
\hline Metoprolol & & 267.36 & $>1.0 \mathrm{E} 4$ & 1.88 & $\begin{array}{l}14.09 \text { (acidic) } \\
9.67 \text { (basic) }\end{array}$ \\
\hline Propranolol & & 259.35 & 228.0 & 2.60 & $\begin{array}{l}13.84 \text { (acidic) } \\
9.50 \text { (basic) }\end{array}$ \\
\hline
\end{tabular}


Acebutolol

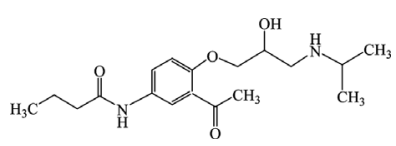

Atenolol

Fluoxetine
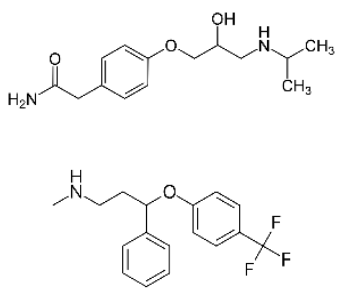

Citalopram

Amphetamine

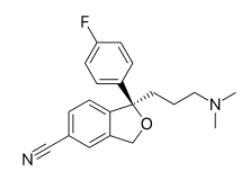

( $\mathrm{CH}_{3}$
336.40

266.34

309.33

324.40

135.21
259.0

685.2

60.3

31.1

2.8E4
13.91 (acidic)

9.57 (basic)

13.88 (acidic)

10.05 (basic)
1.76

9.43 (basic)

$-0.03$

4.65

9.78

9.94 (basic) 
Table S2. Properties of collected soil

\begin{tabular}{ll}
\hline Soil property & Result \\
\hline $\mathrm{pH}$ & $6.6 \pm 0.1$ \\
Moisture content $(\%)$ & $26.3 \pm 0.6$ \\
Specific surface area $\left(\mathrm{m}^{2} / \mathrm{kg}\right)$ & 667 \\
Cation exchange capacity $(\mathrm{meq} / 100 \mathrm{~g})$ & 17.5 \\
$\mathrm{~d}_{10}(\mu \mathrm{m})$ & 3.68 \\
$\mathrm{~d}_{50}(\mu \mathrm{m})$ & 35.6 \\
$\mathrm{~d}_{90}(\mu \mathrm{m})$ & 277 \\
Loss on ignition @ $450^{\circ} \mathrm{C}(\%)$ & $6.2 \pm 0.2$ \\
Loss on ignition @ $900^{\circ} \mathrm{C}(\%)$ & $8.4 \pm 0.1$ \\
\hline
\end{tabular}


Table S3. Mass spectrometry information for studied drugs

\begin{tabular}{|c|c|c|c|c|c|c|}
\hline Drug & Precursor (m/z) & Fragmentor (V) & Product $1(\mathrm{~m} / \mathrm{z})$ & Collision energy (eV) & Product $2(\mathrm{~m} / \mathrm{z})$ & Collision energy $(\mathrm{eV})$ \\
\hline$R / S( \pm)$-naproxen & 231.1 & 90 & - & - & - & - \\
\hline$R / S( \pm)$-ibuprofen & 224.2 & 50 & - & - & - & - \\
\hline$R / S( \pm)$-chlorpheniramine & 274.9 & 90 & 229.9 & 10 & 166.8 & 40 \\
\hline$R / S( \pm)$-salbutamol & 239.9 & 90 & 165.9 & 10 & 147.9 & 10 \\
\hline$R / S( \pm$ )-bisoprolol & 326.2 & 120 & 116.0 & 10 & 74.1 & 30 \\
\hline$R / S( \pm)$-metoprolol & 268.1 & 110 & 191.1 & 10 & 116.0 & 12 \\
\hline$R / S( \pm)$-propranolol & 259.9 & 110 & 182.9 & 10 & 115.9 & 10 \\
\hline$R / S( \pm)$-acebutolol & 337.2 & 90 & 319.3 & 10 & 116.1 & 20 \\
\hline$R / S( \pm)$-atenolol & 266.9 & 100 & 189.9 & 20 & 145.0 & 30 \\
\hline$R / S( \pm)$-fluoxetine & 309.8 & 90 & 147.7 & 2 & 44.0 & 10 \\
\hline$R / S( \pm)$-citalopram & 325.0 & 130 & 262.0 & 20 & 108.9 & 30 \\
\hline$R / S( \pm)$-amphetamine & 135.8 & 70 & 90.9 & 20 & 65.0 & 40 \\
\hline$R / S( \pm)$-naproxen- $\mathrm{d}_{3}$ & 234.1 & 90 & - & - & - & - \\
\hline$R / S( \pm)$-ibuprofen- $\mathrm{d}_{3}$ & 227.2 & 50 & - & - & - & - \\
\hline$R / S( \pm)$-chlorpheniramine- $\mathrm{d}_{6}$ & 281.0 & 100 & 229.9 & 10 & - & - \\
\hline$R / S( \pm)$-salbutamol- $\mathrm{d}_{3}$ & 243.0 & 90 & 150.9 & 10 & - & - \\
\hline$R / S( \pm)$-bisoprolol- $\mathrm{d}_{5}$ & 331.2 & 120 & 121.0 & 10 & - & - \\
\hline$R / S( \pm)$-metoprolol- $\mathrm{d}_{7}$ & 275.2 & 110 & 123.0 & 15 & - & - \\
\hline$R / S( \pm)$-propranolol- $\mathrm{d}_{7}$ & 267.0 & 110 & 115.9 & 20 & - & - \\
\hline$R / S( \pm)$-acebutolol- $\mathrm{d}_{5}$ & 342.2 & 90 & 121.0 & 20 & - & - \\
\hline$R / S( \pm)$-atenolol-d $\mathrm{d}_{7}$ & 274.1 & 100 & 145.0 & 30 & - & - \\
\hline$R / S( \pm)$-fluoxetine- $\mathrm{d}_{6}$ & 316.0 & 90 & 44.1 & 10 & - & - \\
\hline$R / S( \pm)$-citalopram-d $\mathrm{d}_{6}$ & 331.0 & 130 & 109.0 & 30 & - & - \\
\hline$R / S( \pm)$-amphetamine- $\mathrm{d}_{11}$ & 147.0 & 70 & 98.0 & 20 & - & - \\
\hline
\end{tabular}


Table S4. Method performance data for studied drugs

\begin{tabular}{llll}
\hline Enantiomer & Linear range $\left(\boldsymbol{\mu g} \mathbf{~ m L}^{-1}\right)$ & Method trueness $(\%)$ & MQL $\left(\mathbf{n g ~ ~ ^ { - 1 } )}\right.$ \\
\hline$R(-)$-naproxen & $0-100$ & $89 \pm 8$ & 17.9 \\
$S(+)$-naproxen & $0-100$ & $92 \pm 11$ & 20.4 \\
$R(-)$-ibuprofen & $0-100$ & $100 \pm 6$ & 98.0 \\
$S(+)$-ibuprofen & $0-100$ & $103 \pm 7$ & 134 \\
$S(+)$-chlorpheniramine & $0-1$ & $86 \pm 9$ & 0.07 \\
$R(-)$-chlorpheniramine & $0-1$ & $77 \pm 1$ & 0.07 \\
Salbutamol E1 & $0-1$ & $94 \pm 6$ & 0.26 \\
Salbutamol E2 & $0-1$ & $98 \pm 5$ & 0.30 \\
Bisoprolol E1 & $0-1$ & $102 \pm 1$ & 0.12 \\
Bisoprolol E2 & $0-1$ & $104 \pm 2$ & 0.12 \\
Metoprolol E1 & $0-1$ & $102 \pm 1$ & 0.71 \\
Metoprolol E2 & $0-1$ & $104 \pm 2$ & 0.74 \\
$S(-)-$ propranolol & $0-1$ & $101 \pm 5$ & 0.08 \\
$R(+)$-propranolol & $0-1$ & $102 \pm 6$ & 0.07 \\
Acebutolol E1 & $0-1$ & $90 \pm 4$ & 0.10 \\
Acebutolol E2 & $0-1$ & $85 \pm 2$ & 0.11 \\
$S(-)$-atenolol & $0-1$ & $92 \pm 3$ & 0.81 \\
$R(+)$-atenolol & $0-1$ & $98 \pm 6$ & 0.69 \\
$S(+)$-fluoxetine & $0-1$ & $72 \pm 3$ & 0.10 \\
$R(-)$-fluoxetine & $0-1$ & $72 \pm 4$ & 0.07 \\
$S(+)$-citalopram & $0-1$ & $101 \pm 6$ & 1.31 \\
$R(-)$-citalopram & $0-1$ & $104 \pm 9$ & 1.21 \\
$S(+)$-amphetamine & $0-1$ & $113 \pm 2$ & 0.17 \\
$R(-)$-amphetamine & $0-1$ & $110 \pm 2$ & 0.15 \\
\hline
\end{tabular}

Key: MQL, method quantitation limit 


\section{References}

US EPA (2015) Estimation Programs Interface Suite ${ }^{\mathrm{TM}}$ for Microsoft ${ }^{\circ}$ Windows, v 4.11]. United States Environmental Protection Agency, Washington, DC, USA. 